\title{
Phonological knowledge and speech comprehension
}

\author{
Philip J. Monahan
}

Version Accepted Manuscript

Citation Monahan PJ. 2018. Phonological Knowledge and Speech Comprehension. Annu. Rev.

(published Linguist. 4(1):21-47 https://doi.org/10.1146/annurev-linguistics-011817-045537 version)

Publisher's Posted with permission from the Annual Review of Linguistics, Volume 4 by Annual Reviews, Statement http://www.annualreviews.org.

How to cite TSpace items

Always cite the published version, so the author(s) will receive recognition through services that track citation counts, e.g. Scopus. If you need to cite the page number of the author manuscript from TSpace because you cannot access the published version, then cite the TSpace version in addition to the published version using the permanent URI (handle) found on the record page.

This article was made openly accessible by $U$ of $T$ Faculty. Please tell us how this access benefits you. Your story matters. 


\title{
Phonological Knowledge and Speech Comprehension
}

\author{
Philip J. Monahan \\ Centre for French and Linguistics, University of Toronto Scarborough \\ Department of Linguistics, University of Toronto
}

Corresponding Author:

Philip J. Monahan

Centre for French and Linguistics

University of Toronto Scarborough

1265 Military Trail

Toronto, ON M1C 1A4

Canada

Phone: +1 (416) 287-7149

e-mail: philip.monahan@utoronto.ca

Words: 10041

Figures: 3 (2 large, 1 small)

References: 199

Sidebars: 1 


\section{Table of Contents}

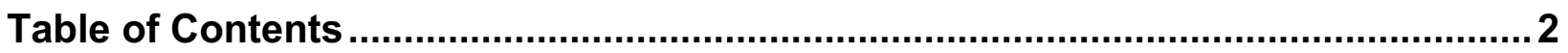

Abstract

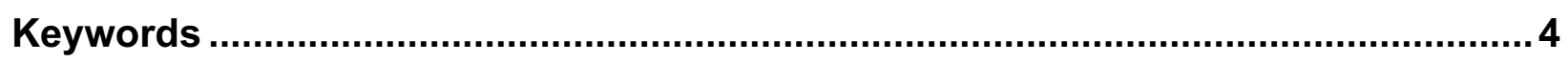

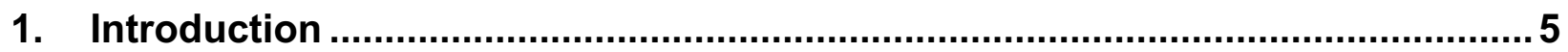

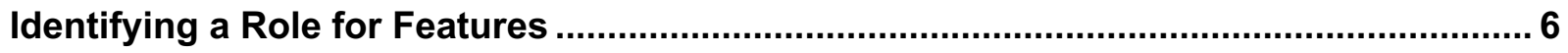

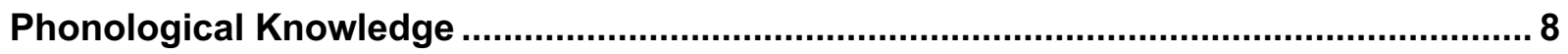

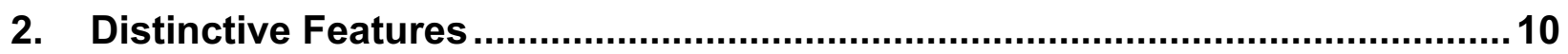

The Organization and Nature of Features …….........................................................12

Physical Bases for Features ....................................................................................... 13

Role in Models of Spoken Word Recognition ............................................................. 16

Previous Psycholinguistic Evidence for Features ……............................................. 18

Privative Features Predict Asymmetric Perception …….............................................21

3. Predicting Speech: Revisiting Analysis-by-Synthesis ....................................22

4. Neurophysiology of Speech Comprehension ..................................................25

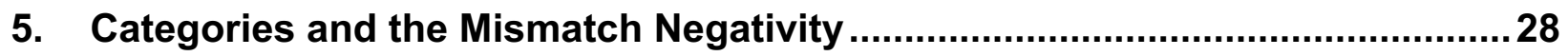

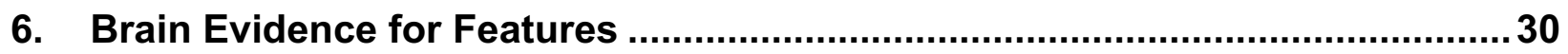

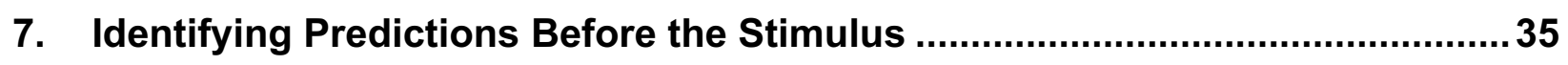

8. Outstanding Issues and Future Directions...................................................... 39

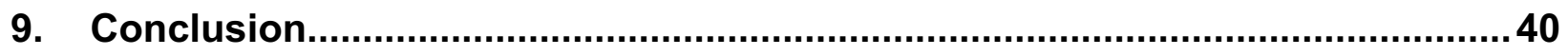

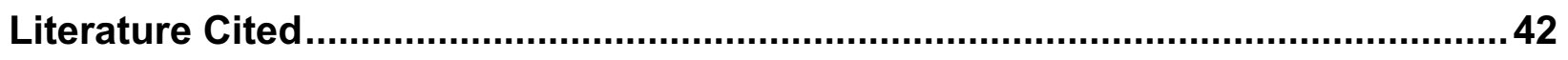




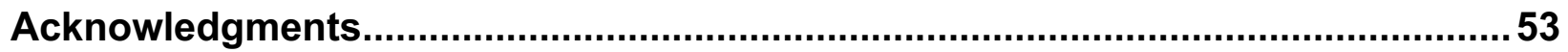

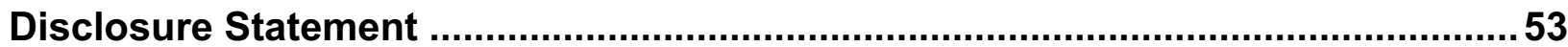

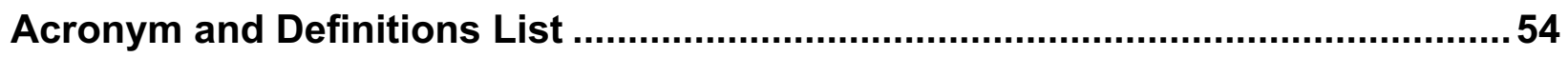

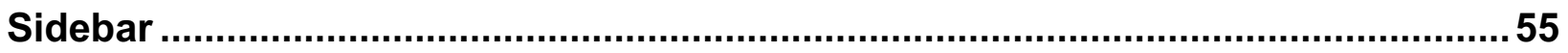

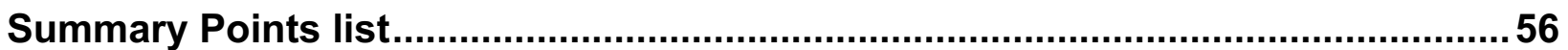




\section{Abstract}

Comprehending speech in our native language is an impressionistically effortless and routine task. We often give little consideration to its complexity. Only in particularly challenging situations (e.g., in noisy environments, when hearing significantly accented speech) do some of these intricacies become apparent. Higher-order knowledge constrains sensory perception and has been demonstrated to play a crucial role in other domains of human language processing. Moreover, incorporating measures of brain activity during online speech comprehension has just begun to highlight the extent to which top-down information flow and predictive processes are integral to sensory perception. This review argues that our phonological system, at a relatively abstract level, is one such source of higher-order knowledge. In particular, I discuss the extent to which phonological distinctive features play a role in perception and predictive processing during speech comprehension with reference to behavioral and neurophysiological data. This line of research represents a tractable linking of linguistic theory with models of perception and speech comprehension in the brain.

\section{Keywords}

Psycholinguistics, Speech Perception, Cognitive Neuroscience, Distinctive Features, Prediction, Speech Comprehension 


\section{Introduction}

Human speech is complex, variable, and dynamic. It is rich in detail and provides listeners with cues to both the "what" and "who" of the utterance. Moreover, speech is intrinsically transient. In unrecorded conversation, listeners cannot revisit and reanalyze earlier portions of the signal should a misinterpretation arise. In addition to its transient nature and rich detail, human speech is highly variable, with considerable physical variation attributable to speaker-intrinsic differences (Peterson \& Barney 1952, Potter \& Steinberg 1950) and speaking rate (Gay 1968, Miller \& Volatis 1989), among other variables. Despite these apparent complexities, we regularly select from this rapidly transmitted code the intended word(s) from an inventory of tens of thousands of possibilities. How this is possible remains a challenging psychological puzzle.

Early efforts to identify systematic relationships between this variable acoustic signal and linguistic segments encountered numerous difficulties (Liberman et al. 1961, 1962). There appear to exist few, if any, reliable or stable cues across different speakers and utterances to individual speech segments (cf. Blumstein \& Stevens 1979, 1980; Miller 1989, Monahan \& Idsardi 2010, Stevens \& Blumstein 1978). A dedicated investigation into how listeners perceive speech began in earnest in the 1950s at the Haskins Laboratories (Liberman 1996). Although the initial goal of this research was to engineer a reading device for the blind, the complexities of both the speech signal itself and its perception quickly became apparent. Coarticulation and phonetic context obscure unique one-to-one mappings between acoustic cues and speech categories (Cooper et al. 1952, Liberman \& Mattingly 1985, 1989; Liberman et al. 1957, 1967). Yet, participants robustly classified speech sounds in a categorical fashion. These 
observations quickly led researchers to abandon their search for unique and reliable acoustic correlates of given speech sounds. Instead, the models they posited emphasized gestural constancy in a special, speech-mode of perception (Liberman \& Mattingly 1985, Liberman et al. 1967). The intuition was that while the acoustic correlates of individual speech segments vary in time and frequency as a function of phonetic context, their intended gestures do not. This position has attracted fierce criticism (Carbonell \& Lotto 2014, Holt \& Lotto 2008, Lotto et al. 2009), but this debate is beyond the scope of this review.

\section{Identifying a Role for Features}

Recent evidence indicates a role for putatively abstract properties of speech sounds (i.e., distinctive features) during perception and suggests that the brain appears to be able to generate predictions that reflect properties of these features. Behavioral, neurophysiological, and neuroimaging techniques have recently been used to investigate the spatial and temporal dynamics of distinctive feature encoding and processing in the human brain. Given the central importance of distinctive features in phonological theory, converging evidence from a variety of methodologies and approaches for the existence of features is desirable.

The last 60 years have taught us that listeners integrate a range of sensory cues and higher-order knowledge during language processing. These sensory cues arise from linguistic knowledge, world knowledge, and non-auditory sensory cues (Gick \& Derrick 2009, Hagoort et al. 2004, Kraljic \& Samuel 2011, McGurk \& MacDonald 1976, Sumby \& Pollack 1954, van Wassenhove et al. 2005, 2007). In other cognitive domains, accounts of perception in the brain have highlighted a strong role for the generation and testing of predictions to facilitate parsing incoming sensory information. Notably, these 
accounts have been proposed in language comprehension (Leonard \& Chang 2014, Molinaro et al. 2016) and sensory perception, more generally (Arnal \& Giraud 2012-b; Bar et al. 2006, Rao \& Ballard 1999, Yuille \& Kersten 2006). Prediction- and expectation-based effects during language processing are observed at a variety of linguistic levels (Kuperberg \& Jaeger 2016), including intra-word (Ettinger et al. 2014), intra-sentential and lexical-semantic (Federmeier 2007, Kutas \& Hillyard 1980, Lau et al. 2008, Maess et al. 2016, Schuberth \& Eimas 1977), and discourse-level processing (Kandylaki et al. 2016). Word-to-word based predictions are quite well established. The goal of this review is not to argue for a primacy of distinctive feature-based predictions during perception but rather to review a set of findings that indicate a role of distinctive features during language processing, and in particular, suggest that the perceptual system can generate and test predictions based on the basis of their properties.

Identifying a role for phonological distinctive features during speech comprehension with perceptual and neurophysiological responses represents a promising avenue in our attempt to link linguistic theory with perception and the brain. To that end, we should be concentrating on connecting representational or computational primitives that have survived theoretical advances with our neuro- and psycholinguistic models (see Poeppel 2012 for a similar position). For detailed reviews of cognitive models of speech perception and spoken word recognition, see Diehl, Lotto and Holt (2004), Jusczyk and Luce (2002) and Samuel (2011).

Despite the central role of distinctive features in phonological theory, evidence for them during speech comprehension and perception is currently inconsistent. The research described in this review, however, points toward emerging evidence in support 
of their role in language processing. Still, the range of methodologies and experimental paradigms from which these conclusions are drawn is narrow and often evidence for features is often difficult to discern from purely acoustic-phonetic explanations. For this reason, a myriad of approaches is necessary to ascertain whether representational objects like distinctive features are relevant units of perception as is assumed in numerous computational models of language processing (see Section 2). The broader the range of evidence in support of features, the more difficult it will be to reduce our explanations for various perceptual phenomena to purely acoustic accounts.

\section{Phonological Knowledge}

Language builds larger meaningful units and structures out of smaller, meaningless units. Hockett (1960) refers to this design feature of language as "duality of patterning", noting that the English words "act", "tack" and "cat" are distinct lexically and semantically. Yet, these three distinct words are composed of the same three segments in three unique combinations. Phonology represents the study of the properties of these smaller, meaningless units (e.g., distinctive features, segments/phonemes, syllables, metrical feet) and the limits on how they can be ordered and recombined both within a language and crosslinguistically. In terms of understanding language as a cognitive system, phonology is the study of the mental knowledge and representation of human language sound systems (Halle 2002, Idsardi \& Monahan 2016). ${ }^{1}$ Within the generative linguistic tradition, phonology is concerned with understanding the mapping between surface, phonetic forms and postulated underlying, abstract lexical representations. Special attention is devoted to the role of phonotactic context in explaining hallmark

\footnotetext{
${ }^{1}$ This discussion focuses on spoken human language. For background on the phonological systems of signed languages, see Brentari (2011).
} 
phonological phenomena, such as assimilation, dissimilation and harmony (Chomsky \& Halle 1968, Prince \& Smolensky 2004). Although the processes that dictate this mapping have evolved in various iterations of generative phonological theory, this core notion of relating a surface "phonetic" form to its underlying lexical representation persists.

This position is antithetical to exemplar and episodic models of speech comprehension and the lexicon that advocate a relatively sympathetic mapping between signal and memory (Goldinger 1996, Johnson 1997, Klatt 1989), as well as general critiques of formal phonology (Coleman 1998, 2003; Port \& Leary 2005). Some researchers have argued for a clear distinction between phonetic and phonological levels of representation during perception (Phillips 2001, Werker \& Logan 1985), although evidence for a distinct phonological level is tenuous at best in perception tasks: Most of the evidence presented by Phillips (2001) in support of a unique phonological level arises from the primary linguistic literature. Moreover, listeners often show sensitivity to within-category variation under certain task demands (but see Altmann et al. 2014 for recent behavioral and magnetoencephalographic evidence that within-category discrimination is much stronger for vowels than consonants) (e.g., McMurray et al. 2002, 2008), suggesting that gradient phonetic cues affect perception, potentially obfuscating observable distinctions between phonetic- and phonological-level perception. Evidence in favor of abstract phonological features in perception and in particular, generalizations across category classes, as discussed here, is difficult to reconcile with approaches that eschew discrete, symbolic, category-level representations. 


\section{Distinctive Features}

A considerable range of hypotheses has been proposed for what constitutes the representational object of speech perception and phonology. In perception, both auditory and articulatory accounts have been offered. These accounts differ in whether the objects of perception are spectral (Klatt 1989), episodic (Goldinger 1996, Johnson 1997), featural (Stevens 2002), or syllabic in nature (Grossberg 1999), or from an articulatory perspective, whether they are the intended (Galantucci et al. 2006, Liberman \& Mattingly 1985) or actual gestures (Fowler 1996). In gestural phonology, some researchers claim the atomic phonological units are the actions of the vocal tract (Browman \& Goldstein 1989), whereas others have argued that positional information (i.e., something that approximates allophones) of segments must be encoded in phonetically rich lexical representations (Pierrehumbert 2003).

The idea is that speech sound categories in a language are not holistic units but rather constellations of features has persisted throughout advances in phonological theory (Chomsky \& Halle 1968, Clements 1985, Jakobson et al. 1961, McCarthy 1988). The background assumption is that lexical storage should be economical, representing only unpredictable knowledge that cannot be derived from linguistic processes (Halle \& Clements 1983). That higher-order concepts in other cognitive domains are composed of features is not unique to speech sound systems either. This idea has been postulated in visual object representation (Dressler 1984, Ullman et al. 2002) and has a long tradition in theories of semantic representation (see Katz \& Fodor 1963). These phonological distinctive features, although traditionally cached in articulatory terms, serve as an abstract link between articulation and audition (Halle 2002). Furthermore, 
they provide specification for various properties of speech sounds. For example, the aspirated bilabial plosive $\left[p^{h}\right]$ in a language like English (e.g., ['ph $\left.{ }^{h \tilde{n}}\right]$ pin), is (partially) composed of the following features: [+consonantal; +plosive; +labial; -voiced;

+aspirated]. Again, although these features appear to reference only the articulatory dimensions of the category, this is done out of illustrative convenience. One should take [+plosive], for example, to link the articulation of a brief, complete occlusion of the oral cavity followed by its release to the auditorily ephemeral, sudden burst of intense spectral energy across a relatively narrow-frequency band.

These features do not exist solely as taxonomic classifiers in a language's sound system but rather, importantly, serve to explain the natural class behavior of how phonological categories pattern within and across languages. Regarding the plosive example above, in English, voiceless plosives are aspirated when they are the initial consonant in a stressed syllable's onset (e.g., ['phĩn] pin, ['thĩn] tin, ['khĨn] kin), and liquids in English are voiceless following an aspirated plosive (e.g., ['ph!ææn] $]^{*}\left[p^{h} \mid \tilde{e n}\right]$

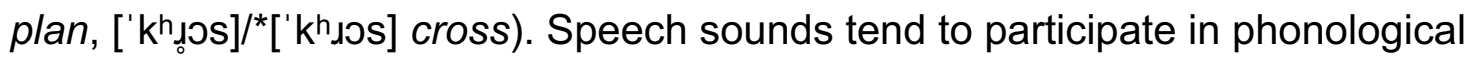
alternations as members of natural classes. For instance, liquids are devoiced following an aspirated plosive in English (as in the above example), and velars in Polish become palatalized preceding the high front vowel /i/ (Dressler 1984). ${ }^{2}$ Phonological distinctive features provide an elegant account of this behaviour.

2 See Mielke (2008) for counterexamples to natural class behavior in phonological systems and arguments against the innate nature of specific features and feature classes. 
The Organization and Nature of Features

The organization of these features within segments has also seen various changes. In the so-called Sound Pattern of English framework (Chomsky \& Halle 1968), features are assumed to be unordered bundles that lacked structured relationships between them. In an attempt to account for various auto-segmental and long-distance phonological phenomena, it was subsequently proposed that features are instead hierarchically structured (Clements 1985, McCarthy 1988). In this way, phonological rules could be written to target specific tiers or nodes in the feature space, potentially explaining why consonants can be transparent to rules that target vowel features (e.g., vowel harmony).

Another debate in the literature has focused on the representation of features, an issue that is more pertinent to the current discussion. Initially, features were thought to be binary, or equipollent (Chomsky \& Halle 1968). That is, each feature for each segment in a language's inventory has a polarity associated with it (e.g., a vowel is either [+round] or [-round], and a consonant is either [+nasal] or [-nasal]), and each member of a category opposition receives a feature specification (e.g., [n] is [+nasal], whereas [d] is [-nasal]). Binary feature systems wrongly predicted that both positive and negative specifications should denote active natural classes in the phonological grammar (van der Hulst 2016). Subsequently, monovalent, or privative, features were proposed (Clements 1985, Harris \& Lindsey 2002, Lombardi 1991, Sagey 1986). For example, a nasal segment contains the feature [nasal], whereas a nonnasal segment would completely lack the feature. This privative system of features predicts that only the present, active feature can be the target of or initiate phonological processes in the language. Various models of phonological feature specification, including underspecification accounts (Steriade 2005), have adopted this privative feature 
approach. Different varieties of underspecification exist and these varieties make different predictions with respect to the organization of the phonological system. Yet, the underlying similarity is that predictable feature specifications are omitted from a speech sound's long-term representation (Archangeli 1988, Mester \& Itô 1989). The most canonical example is the coronal nasal segment [n], whose place of articulation is typically determined by its local context. That is, it often assimilates in place of articulation to the place of a following consonant (e.g., lea[m] bacon "lean bacon" but not *ga[n]e time "game time"). Otherwise, it has the putative default place of articulation [coronal]. A central debate within the phonological literature is whether underspecification is inventory driven (Avery \& Rice 1989) or rule driven (Archangeli 1988). Another debate is whether all non-contrastive, predictable feature values are underspecified in the lexicon (Mohanan 1991) or whether only segments that are contrastive in a given language's inventory are specified (Steriade 2005).

\section{Physical Bases for Features}

Regarding the physical bases for distinctive features, it has been argued that language exploits relatively stable portions in the articulatory-acoustic space to build its phonetic and phonological contrasts. Specifically, there are regions in this space where large articulatory changes cause relatively minor acoustic-auditory differences. Between these stable regions, however, small articulatory changes can cause drastic acousticauditory differences. Distinctive features are the correlates of these stable regions of the space and language exploits these quantal relationships for phonetic and phonological contrasts (Stevens 1989). Stevens and Hanson (2010) argue for two "sources" of quantal relationships: aerodynamic forces and coupled resonators. In particular, these quantal relationships define two broad classes of distinctive features: articulator-free 
features (e.g., [sonorant], [strident]) and articulator-bound features (e.g., [high], [lateral]), respectively (see also Stevens \& Keyser 2010). Recent computational simulations of laryngeal functioning during speech articulation suggest a number of quantal relationships (mostly tissue-on-tissue contact) in the biomechanics of the larynx and support a modular view of speech-motor control (Moisik \& Gick 2017).

Evidence for these quantal relationships is robust in investigations of the articulatory and acoustic relationships present in speech. Their support from perception, however, is less robust. Johnson and Babel (2010) attempted to identify a perceptual basis for innate, universal distinctive features by testing English and Dutch participants on English fricatives. In a rating task, Dutch listeners, compared with English listeners, rated [s] and [], which stand in a quantal relationship, as being more similar. This is expected, as the two segments are phonemic in English and allophonic in Dutch. In a follow-up speeded discrimination experiment, a paradigm intended to access more automatic properties of speech sound processing, the listener's language background had no effect, suggesting that Dutch listeners, under certain task demands, discriminate these two sounds as robustly as English listeners. This is potentially evidence that the quantal relationships, and by proxy, distinctive features, are universal and innate and that evidence for them can arise under certain task demands in listeners whose language does not encode that particular contrast.

There are some issues with this conclusion, however. First, as Johnson and Babel (2010) note, there is evidence from their rating experiment that these ratings were likely based on auditory similarity and not higher-order, language-specific representations, making a comparison of effects between the two experiments difficult. 
Second, it is unclear whether all contrasts tested stood in a quantal relationship (e.g., [f] and []]). If this contrast did not show a language effect (note that it is phonemic in English and not in Dutch; for the reverse condition, $[\mathrm{x}]$ and $[\mathrm{h}]$, which are not phonemic in English, were also tested), then the extent to which it is the innate quantal relationship between [s] and [] that results in the Dutch listeners' performance in the speeded discrimination task is doubtful. Finally, a number of studies show language effects in discrimination tasks (Best \& Strange 1992, MacKain et al. 1981). As such, understanding whether listeners have access to these universal, innate quantal relationships during perceptual tasks remains unanswered. Stronger tests that compare phonetic/phonological contrasts with sounds that stand in quantal relationships versus those that do not are required.

How these features are derived remains a point of debate. Whereas it had been traditionally assumed that these features were innate (Chomsky \& Halle 1968, Stevens \& Hanson 2010), alternative proposals have stressed the role of both the lexicon and the acquisition of phonological contrasts. The alternative view is that these features emerge during acquisition. According to Mielke (2008, p. 9), "[i]n emergent feature theory, features are abstract categories based on generalizations that emerge from phonological patterns. In innate feature theory, it is typically the other way around: phonological patterns emerge (at least in part) from the effects of features." For example, both Lindblom (1992) and Beckman \& Pierrehumbert (2004) emphasize the role of lexical development and contrast. Specifically, Beckman \& Pierrehumbert (2004) reject the notion that these features are innate and instead argue that these discontinuities in the articulatory--acoustic space interact with the demands for lexical 
distinction directly. They emphasize the role of contrasting word forms and the influence they exert on structuring the phonological system of a given language. Like Lindblom (1992), Mielke (2008) argues that features emerge during the acquisition process, although he places less of an emphasis on lexical influence and more of an emphasis on the phonetic and phonological patterns themselves in a language. Similarly, Dresher $(2015 a, b)$ rejects the notion that features are innate but posits that the ultimate feature space arrived upon by the child learner is a consequence of identifying the relevant contrasts in the ambient language in an ordered manner, eventually arriving at a contrastive feature hierarchy.

By contrast, Hale and Reiss (2008) and Reiss (2017) advocate for innate, phonological features and argue that phonological contrasts cannot be derived from phonetic observations alone on the part of the learner, as these observations require a phonological system. Additionally, the primacy of phonetic cues in deriving the feature inventory of a language appears to be inadequate, as there are phonological representations inconsistent with the acoustic-phonetic patterns of the input (see the Classical Manchu vowel system data in Dresher 2015a).

\section{Role in Models of Spoken Word Recognition}

The extent to which representations and processes proposed by phonologists have any import in speech comprehension has been both staunchly criticized (Goldinger \& Azuma 2003, Sussman 2000) and incorporated into relatively explicit (although not computationally implemented) models of speech comprehension (Stevens 2002). Recent perceptual and neurophysiological findings have suggested that these representations and processes provide coherent explanations for various observed phenomena (Berent 2013). 
Subsegmental features have been assumed both implicitly and quite explicitly in numerous psycholinguistic models. TRACE, a well-known parallel-distributed connectionist model of word recognition (McClelland \& Elman 1986), assumes that the sensory input to the model was in the form of distinctive features. This is also the case for the Cohort (Marslen-Wilson 1987), Shortlist (Norris 1994, Norris \& McQueen 2008), and MERGE (Norris et al. 2000) models of spoken word recognition. In production, several accounts and computationally explicit models have assumed distinctive features as the output of the production system (Dell et al. 1993, Levelt et al. 1999, Mowrey \& MacKay 1990, Roelofs 1999). In his forward model of motor control and production, Hickok (2014) assumes feature-level representations (in addition to syllables) for both perception and production, whereas the phoneme exists only in production. In each of these cases, however, it is not clear how critical it is to posit a feature level of representation or to what extent these features are the same as those proposed by phonologists. For the TRACE model, one could argue that this is an assumption of convenience. That is, some representations are necessary to get activation flow in the network but they need not be of the distinctive feature variety, or at least abstract and discrete in nature. In fact, Norris \& McQueen (2008, p. 326) are quite agnostic with regard to the precise nature of the sensory input to their Shortlist B model-although they note that it must be of some abstract variety (cf. Goldinger \& Azuma 2003, Johnson 1997, Port \& Leary 2005):

Spoken-word recognition appears to be mediated by the recognition of phonologically abstract sublexical units at a prelexical level of processing [...]. A number of units could serve this function, including (bundles of) features, 
phonemes, and position-specific allophones. It remains to be determined which of these alternatives is the most plausible. In Shortlist $B$, as indeed in Shortlist $A$, we make the assumption that these units are phonemes. It is important to stress, however, that this is only a working assumption; we have no reason to commit to phonemes as the prelexical unit of representation.

In Hickok's (2014) account of production, auditory and motor features are presumed to serve as the sensory input to higher levels of representation (syllables, phonemes), but again, it is not clear to what extent these are akin to those proffered by phonologists.

\section{Previous Psycholinguistic Evidence for Features}

We have known for some time that speech segments that belong to similar classes are consequently more confusable when masked by noise than those that do not belong to the same class (Miller \& Nicely 1955, Wang \& Bilger 1973). Confusion matrix data show that under noise-masking conditions (for example, when masked by broadband noise at a signal-to-noise ratio of $-6 \mathrm{~dB}$ ), the segment [p] is likely to be confused with [t] or [f] but never with [z] or [n] (Miller \& Nicely 1955). Insofar as natural classes are evidence for the existence of phonological distinctive features, confusion data of this sort suggest that listeners access these feature-level representations during perception. Although these data are often taken to support feature-based processing (Mielke 2008, Stevens \& Hanson 2010), it is certainly possible to account for Miller \& Nicely's (1955) findings with a purely acoustic account; for example, the reason that $[\mathrm{p}]$ is often confused with [t] under noise-masked conditions and not with $[\mathrm{z}]$ is because $[\mathrm{p}]$ and $[\mathrm{t}]$ are more acoustically similar than [p] and [z]. In fact, Soli \& Arabie (1979) tested Miller \& Nicely's (1955) data with a multidimensional scaling analysis and found that a four-dimensional 
solution based on acoustic parameters fared better in accounting for the variance observed by Miller \& Nicely (1955) than a feature account.

In a dichotic listening study in which listeners heard pairs of words, one presented to each ear, Studdert-Kennedy and Shankweiler (1970) observed that pairs of segments that share features were more accurately identified than pairs that do not share features. Specifically, pairs that shared place-of-articulation features were more often correctly identified than those that shared only voicing features. In a follow-up study, Studdert-Kennedy et al. (1972), tested a similar paradigm, but either varied the vowel between the two members of the pair or kept the vowel the same. Changing the vowel changes the nature of the formant transitions, an acoustic cue that helps listeners identify a segment's place of articulation. Studdert-Kennedy et al. (1972) observed that there was no effect of the vowel in participants' identification responses. That is, if listeners' behavior solely reflected differences in acoustic cues, then listeners should have shown fewer errors when the vowel was the same (i.e., similar acoustic cues) than when the vowel differed. The fact that there was no such effect of vowel suggests that the listeners were accessing higher-level representations, possibly representations consistent with a distinctive feature-level account (Mielke 2008).

Eimas and Corbit (1973) used a selective adaptation paradigm to test for the existence of what they term linguistic feature detectors. They synthesized two voiceonset time (VOT) continua, i.e., /ba-pa/ and /da-ta/ that differed only in VOT of the initial consonant. The logic behind their selective adaptation paradigm was that repeated exposure to one category would fatigue the feature detectors responsible for identifying that sound and cause a perceptual shift toward the category at the other end of the 
continuum. They found that repeated exposure to [d] with a 0-ms VOT led to more /t/ identification responses, and vice versa, across the /d-t/ continuum. Crucially, they also included conditions in which, for example, participants would be adapted to the bilabial [b] and asked to identify tokens from the /d-t/ continuum. Their results demonstrate that selective adaptation occurred across place-of-articulation contrasts; for instance, repeated exposure to [b] with a -10-ms VOT resulted in more [t] responses along a /d-t/ continuum. In fact, the authors found equal-size adaptation effects when comparing the intra-place comparisons with the inter-place comparisons. Finding selective adaption across consonant places of articulation suggests that listeners are not relying on phonetic representations alone, or even holistic segmental representations in this paradigm. Instead, they must be accessing sub-segmental cues, likely at the level of the distinctive feature. Similar findings have also been reported in perceptual learning paradigms. In these experiments, participants are typically presented with words and non-words during an exposure phase and asked to make a lexical decision. One segment within the word is presented as an ambiguous sound, as in luna[?td]ic "lunatic", in which the medial coronal stop has a VOT halfway between /t/ and /d/, whereas lexical items with the other segment are presented naturally, as in residence "residence". Participants learn that one segment has a non-standard pronunciation during the exposure phase whereas the other has a standard pronunciation. In a subsequent categorization task during the test phase, the listeners identified more tokens along the continuum as the non-standard category heard during the exposure phase. McQueen et al., (2006) found perceptual learning across an [f-s] fricative continuum and found generalization to novel words not in the exposure phase, and Kraljic and Samuel (2006) 
found that perceptual learning in stop VOT continua also generalizes to other places of articulation. Similar to the findings of Eimas and Corbit (1973), these results appear to support sub-lexical and potentially feature-level representations. That is, generalization to novel lexical items and in particular, novel category pairs would be a straightforward prediction if phonological distinctive features played a role in perception. Features have also been implicated in an account of the perception of assimilated phonetic sequences (Gow 2003). In this account, assimilation patterns are best explained by perceptual grouping along feature lines allowing listeners to recover the underlying place of articulation of assimilated targets.

\section{Privative Features Predict Asymmetric Perception}

The Featurally Underspecified Lexicon (FUL) model of perception and production assumes a radical underspecification theory of distinctive features (Lahiri \& Reetz 2002, 2010). In production, adjacent specified features fill in missing feature values. In perception, recognition is achieved by comparing surface feature values with underlying feature values. This comparison results in three possible outcomes: match, mismatch, or no mismatch. A match would indicate that the surface feature matches the feature specification in the phonological representation, a mismatch would indicate that the surface and phonological representations do not share the same feature specification, and a no mismatch would be a case in which the feature is underspecified in the abstract phonological representation and, as such, there is nothing with which the surface feature mismatches. This model takes a strong position on the types of representations involved in perception, eliminating segmental and syllabic representations (Grossberg 1999, Hickok 2014, Poeppel 2003) and ignoring context during perception (Gaskell \& Marslen-Wilson 1996, Gow 2003, compare with Gow \& Im 
2004). Crucially, however, it makes predictions regarding asymmetries in perception that are discussed in more detail in Sections 6 and 7, below. In particular, mismatch and no mismatch cases should result in distinct behavioural and neurophysiological responses. Although asymmetries have not always been reported when they are predicted (Mitterer 2007), the neurophysiological data reported below are consistent with the hypotheses of the FUL model, allowing us to make specific links between phonological theory and brain responses.

Although the perception- and brain-based evidence presented below does not distinguish between differing hypotheses with regard to the internal organization of features (e.g., unordered bundles versus hierarchical tiers), the data described do appear to favor privative or monovalent feature specifications. That being said, as mentioned in Section 1, the data accrued to date in this regard are limited in scope and are derived from a rather small set of methodological techniques.

\section{Predicting Speech: Revisiting Analysis-by-Synthesis}

Perhaps the most straightforward assumption about how the speech comprehension system may work is that lower-level sensory systems analyze the incoming signal, and the output of these stages of processing is fed forward to higher levels of linguistic representation, for example, spectra to features to segments to syllables to words. This process iterates until a lexical--conceptual representation is reached in the case of word recognition, although such processing stages likely continue through syntactic, semantic, and pragmatic levels as well. The notion of prediction during perception has recently gained considerable traction in accounting for sensory perception and information processing. Moreover, some recent approaches have been inspired by a 
resurgence of interest in an older model of perception from the linguistics literature: Analysis-by-Synthesis (Halle \& Stevens 1962, Stevens \& Halle 1967). This model has been applied to the issue of the visual perception of naturalistic images in a relatively computationally explicit manner (Yuille \& Kersten 2006) and has been more loosely used to interpret various perceptual and neurophysiological responses during language comprehension (Bever \& Poeppel 2010, Poeppel \& Monahan 2011). Broadly, this approach is consistent with predictive coding frameworks in the brain (Arnal \& Giraud 2012, Rao \& Ballard 1999) and top-down, prediction-based approaches to visual object recognition (Bar 2007, 2009a, b) and language comprehension more generally (Molinaro et al. 2016).

In an Analysis-by-Synthesis model of speech comprehension, a preliminary analysis is performed on the signal and a set of guesses as to the intended segment/word is generated (see Figure 1). The system makes these guesses by combining the output of the preliminary analysis with the application of generative rules. A predicted comparison spectrum of the signal is then constructed and compared with the input. This loop continues until a best fit-yet to be explicitly defined-is achieved. What is clear in this model is that hypotheses are actively generated and fed back to be compared with the input spectrum. Moreover, these guesses are based on higher-order knowledge, potentially linguistic or perceptual in nature (see Poeppel \& Monahan 2011 for a more detailed and thorough discussion of the model). This notion of a course analysis of the signal to be filled in later on during subsequent stages of processing is shared by the Landmark model of speech perception (Stevens 2002) and has been integrated into neurobiological models of spoken word recognition (Poeppel et al. 2008). 


\section{INSERT FIGURE 1 ABOUT HERE}

Although various aspects of this model have yet to be tested rigorously, some findings suggest that the core tenets of the system are necessary for any model of speech comprehension. van Wassenhove et al. (2005) interpreted their results of an eventrelated potential (ERP) study (see the sidebar titled Application of Neuroimaging Techniques) of audio-visual speech perception in the context of an Analysis-bySynthesis framework. In particular, visual cues precede auditory cues by approximately 60-200 ms, and certain visual cues are more informative than others; for instance, in English, a bilabial closure indicates that the following sound can only be [p], [b], or [m], and this kind of information will lead to very specific predictions about what listeners expect to hear. Other closures are less specific in their informativity and lead to lessspecific predictions. The ERP responses reflected these specificities. In particular, brain responses sped up while participants viewed audio--visual speech when specific predictions were possible (e.g., [p]), compared with situations when only less-specific predictions were possible (e.g., [ta] or [ka]). These findings suggest that the brain integrates visual information and uses it in a potentially predictive manner---when possible---in processing audio--visual speech. Predictions have also been observed in various behavioral paradigms, often relying on relatively abstract properties of phonological segments and, in particular, features (Hwang et al. 2010, Lahiri \& MarslenWilson 1991). 
Leonard et al. (2016) conducted an experiment with presurgical patients by placing electrode grids [electrocorticography (ECoG)] directly on the surface of left auditory cortex. The listeners heard English words either the original fricative with intact (e.g., 'faster' [fæstr] or 'factor' [fæktr]) or replaced by noise (e.g., [fæ\#tr]). On all trials, the participants had to indicate which of the two words they heard, even in the noise conditions. Subsequently, the researchers identified the electrodes in the array that best differentiated between the original stimuli. Then, they calculated the distance between each noise response (considering how the participant responded on that individual trial) and the original response at those electrode sites. Crucially, they observed perceptual restoration effects in the electrophysiological signal from the temporal onset of the noise-masked segment. This effect was strongest at $150 \mathrm{~ms}$ postonset of the ambiguous phoneme, suggesting a strong and relatively early role for predictive mechanisms in the neurobiology of language processing and speech comprehension more specifically. The time signature is consistent with the above-described findings from audio--visual speech perception and the results described in Section 6 on mismatch negativity $(\mathrm{MMN})$ in electroencephalographic (EEG) and magnetoencephalographic (MEG) research.

\section{Neurophysiology of Speech Comprehension}

Although the remainder of this article emphasizes neurophysiological techniques, a methodologically pluralist approach is advocated and necessary for complete understanding. The findings from brain experiments are promising and represent some of the most compelling evidence to date that phonological features playing a role in perception, yet such a methodologically narrow direction is disfavored in the long run. 
Early auditory evoked responses from the brain's surface grey matter (cortex) and deep white matter (subcortex) are observable with EEG (see Picton (2011) for a review). Responses as early as the first few milliseconds of sensation can be recorded. Often in neurophysiological studies in general, many repetitions of the same or similar stimuli are presented to participants and these repetitions are averaged together on a condition-by-condition basis (see Figure 2A). The averaged response consists of a series of components, namely peaks and valleys in the brain waveform, for which their latency or amplitude can be measured (see Figure 2B for an MMN example). Components are typically named for their polarity in the ERP signal (positive, $\mathrm{P}$, or negative, N) and the time at which they typically occur (e.g., the P2 is a positive deflection in the ERP waveform peaking around 200-ms after the presentation of a stimulus). In the related technique MEG, the letter $m$ is often added to the typical peak time of a component in the event-related field (ERF). Considerable research has attempted to identify the functional roles of these components (Luck 2014), but for the purposes of this review, simple differences in the brain waveforms in predicted directions suffice.

The first robust auditory evoked response to human speech is the N1/M100 (N1m; the ERF counterpart of the ERP N1). This component is sensitive to low-level stimulus characteristics in auditory signal processing, including the frequency of an auditory stimulus, its intensity, its harmonic content (e.g., sinusoidal or square-wave), and the first formant in vowels (e.g., Gage et al. 1998, Roberts et al. 2000).

With respect to speech perception, Toscano et al., (2010) reported that the amplitude of the N1 varied systematically as a function of VOT, with shorter VOTs 
eliciting larger ERP N1 amplitudes. This finding suggests a somewhat low-level encoding of speech-sound characteristics in relatively early, evoked responses. MEG responses to vowel characteristics have shown that the M100 reflects sensitivity to category structure in the native language of the participants (Roberts et al. 2004) and may also reflect more complex speaker normalization algorithms (Monahan \& Idsardi 2010).

\section{INSERT NEUROIMAGING SIDEBAR ABOUT HERE}

Obleser and Eisner (2009) argue for pre-lexical abstraction from the acoustic signal. In particular, they identify Heschl's Gyrus/Primary Auditory Cortex as the region supporting the extraction of acoustic features (e.g., VOT, formant ratios). The Planum Temporale (PT), a region just posterior to the Primary Auditory Cortex supports precategorical responses. Hickok and Poeppel (2007) identify the bilateral Superior Temporal Sulcus (STS) as the region supporting the phonological network and the Medial Temporal Gyrus (MTG) as the location of the lexical network.

Using source localization methods of the evoked N1m response, Scharinger et al., (2011) demonstrated that the eight vowel categories in Turkish all have distinct spatial locations in the auditory cortex. Round vowels localize to more lateral regions, whereas for front vowels, height differs along the superior--inferior plane, and for back vowels, height differs along the posterior--anterior plane. These results are consistent with previous findings that vowels (Obleser et al. 2004) and consonants (Obleser et al. 2003) localize to distinct cortical sources. 


\section{Categories and the Mismatch Negativity}

A prominent tool used to explore the nature of speech sound category representations in the auditory cortex is the MMN (Näätänen 2001, Näätänen \& Kreegipuu 2012, Näätänen \& Winkler 1999, Winkler 2007). The response is automatic and pre-attentive, evidenced by observations made during human and non-human mammalian sleep (Atienza et al. 2002, Csépe et al. 1987, Nashida et al. 2000, Sculthorpe et al. 2009), as well as comatose states (Fischer et al. 2000, Vanhaudenhuyse et al. 2007, Wijnen et al. 2007). Although most research utilizing the MMN has been conducted in the auditory modality, a similar oddball response has been identified in vision (Astikainen et al. 2008, Tales et al. 1999) and olfaction (Sabri et al. 2005). In audition, the peak (negative) amplitude of the response is approximately $150-250-\mathrm{ms}$ postonset of the deviant stimulus over frontocentral scalp sites in EEG recordings (i.e., Fz, Cz) (see Figure 2B), and its neural generators localize to superior regions of the STG (see Figure 2C), approximately 3-10 $\mathrm{mm}$ anterior to the source location of the above-mentioned N100/N1m component (Csépe et al. 1992, Hari et al. 1992, Näätänen et al. 2007, Sams et al. 1991).

\section{INSERT FIGURE 2 ABOUT HERE}

In the context of speech sound representations, the MMN reflects sensitivity to native language categories in both infants (Rivera-Gaxiola et al. 2005) and adults (Näätänen et al. 1997, Sharma \& Dorman 2000, Winkler et al. 1999). For example, Näätänen et al., (1997) demonstrated that Estonian adults had a larger MMN response 
than Finnish adults when the deviant stimulus was a phonemic category in Estonian that does not exist in Finnish (i.e., the mid-back unrounded vowel $[\gamma]$ ). Such experiments do not, however, distinguish between phonetic and phonological representations. In particular, given the lack of acoustic variation in the standards, the data are also compatible with an episodic account of phonetic categorization (Johnson 1997). To address this issue, Phillips et al., (2000) employed a many-to-one oddball paradigm, wherein standards were identical at a category level but not an acoustic level. Previous MMN research demonstrated that the auditory cortex can perceptually group stimuli along a single dimension, while ignoring variability along others (Gomes et al. 1995). In such cases, an abstract representation of the standard is constructed. Using this approach, Phillips, et al., (2000) showed that, in one experimental block, each standard was a token of [t] that varied in VOT, such that no two successive standard tokens were acoustically identical although all were recognizable as " $\mathrm{t}$ ". Despite physical variation in the standards, an MMN to deviant tokens was observed, suggesting that participants constructed a standard representation that abstracted from acoustic details. A model of the perceptual space wherein category-like representations emerge from statistically clustered distributions is also consistent with the findings.

Kazanina et al., (2006) compared native speakers of Korean and Russian in an MMN paradigm employing the same logic in the Phillips et al., (2000) experiments. Both languages have prevoiced [d] and short-lag [t]. In Russian, this pair is phonemic, whereas in Korean, it is allophonic. Kazanina et al., (2006) reported an MMN to deviants only for the Russian participants, suggesting that the MMN indexes abstract phonological representations. That is, the lack of an MMN for the Korean participants 
was attributed to the fact that Korean does not phonologically exploit a voicing contrast. Note, however, that the stimuli in the experiment were of the form CV (i.e., [tæ]/[dæ]). Because the phonetic segment [d] occurs only intervocalically in Korean, utteranceinitial position is not a licit environment for [d], making the interpretation of the null effect in Korean participants difficult. Taken together, these findings suggest that the auditory cortex supports a level of speech sound representations that lacks fine acoustic detail and is sensitive to the phonemic categories in the language, but note that in many models of perception, phonemes are epiphenomenal (Goldinger \& Azuma 2003, Hickok 2014), and instead, evidence for features is desired. The power of the MMN, however, lies in its ability to serve as an index for the range of categories at varying levels of abstraction that can be supported by the auditory cortex. More recent evidence for distinctive features from neurophysiological responses is presented in the next section.

\section{Brain Evidence for Features}

As noted in Section 2, phonological theory posits representations below the level of the segment, where the smallest, most fundamental phonological unit is the distinctive feature (Clements 1985, Halle 2002, Jakobson et al. 1961). Phonological segments are composed of such features that represent an abstract link between a given speech sound's auditory and articulatory properties.

Since 2011, findings in the neurophysiological and neuroimaging literature have supported a feature-level of representation and its role in prediction during online speech comprehension. Recent fMRI research has indicated that broad feature classes

are (at least partially) spatially segregated in human cortex. That is, place, manner, and 
voicing features all localize to (partially) distinct cortical regions (Arsenault \& Buchsbaum 2015, Correia et al. 2015, Lawyer \& Corina 2014). Using an fMRI adaptation experiment, Lawyer and Corina (2014) observed distinct regions in the right MTG and left STG for place and voicing contrasts. Arsenault and Buchsbaum (2015) used multi-pattern voxel analysis (MVPA) to identify regions of bilateral auditory and pre-motor cortex that were sensitive to broad feature classes (Place, Manner, Voicing). Notably, all three classes are represented in bilateral STG, with regions unique to place contrasts observed largely in the right hemisphere and regions that uniquely encode manner and voicing in the left hemisphere. Finally, by using multivariate fMRI decoding, Correia et al. (2015) used multivariate fMRI decoding and found that place- and manner-of-articulation are encoded in bilateral superior temporal cortex and that these activation patterns were independent of non-categorical acoustic variation. More specifically, responses in the STG that distinguished place of articulation in stop consonants predicted the place of articulation of fricatives. Although this line of research is promising in terms of determining the underlying spatial distribution of features in human auditory and premotor cortex, these findings (largely) do not delineate broader feature classes in more specific distinctive feature oppositions of the type described in Section 2. Recent research in presurgical patients and an invasive neurophysiological technique have begun to better map out the cortical spatial distribution of such features.

Presurgical epilepsy and brain tumor patients sometimes undergo ECoG, which is invasive electrode array placement on the surface of the cortex. Such procedures provide the temporal accuracy of EEG and MEG, but superior spatial resolution for regions covered by the electrode array. Chang et al. (2010) measured directly from the 
surface of the auditory cortex of four presurgical participants while they performed discrimination and identification tasks on a [ba]--[da]--[ga] continuum. Using multivariate pattern classification and multidimensional scaling of the brain and behavior data, Chang et al. reported categorical encoding of speech sounds in the posterior STG (pSTG) (Figure 2C). Topographic plots illustrated some spatial separation of the cortical responses to each of the three syllables approximately $110 \mathrm{~ms}$ after the onset of the stimulus.

In a follow-up ECoG study, Mesgarani et al. (2014) found selectivity for particular features at specific electrode sites in the STS. Using a hierarchical cluster--based analysis of the ECoG signal, these authors found that responses for given segments appeared to pattern according to their natural classes, and when the stimuli were defined by their featural components, they observed high intraclass selectivity for the given electrode sites. That is, Mesgarani et al. (2014), advancing the previous fMRI findings, showed that the activation patterns in STS of individual phonetic segments, as opposed to just broad feature classes, largely cluster together with respect to their natural classes. This result provides more straightforward evidence for the idea that distinctive features are neurally encoded. Note that these findings are based on a small sample size of patients $(n=6)$ and that certain unexpected classes patterned together (e.g., the voiced dental fricatives $[v]$ and $[ð]$ were most closely classified with high vowels). The other caveat is that it is difficult in their findings to determine whether these natural class patterns arise from pure acoustic similarity or from more abstract feature representations. That being said, the overwhelmingly clear classification of segments based on neural activation patterns is a considerable step forward and to a large extent 
vindicates natural classes of phonetic and phonological segments. Similar to the confusion data described in Section 2 (Miller \& Nicely 1955, Wang \& Bilger 1973), in so far as we take evidence for responses coinciding with natural classes as evidence for features, these hierarchical statistical models of ECoG data provide novel support for the idea that distinctive features are encoded by the brain.

Regarding the more temporally based measures of behavior, recall that the FUL model of perception predicts asymmetries in brain responses. In a pair of phoneme identification studies, Hwang et al. (2010) reported that reaction times and accuracy to $\mathrm{C}_{2}$, namely [s] or [z], in $\mathrm{VC}_{1} \mathrm{C}_{2}$ contexts differed depending on whether $\mathrm{C}_{1}$ was voiced [d] or voiceless [t] (Hwang et al. 2010). In particular, the incongruent sequence [uds] resulted in slower reaction times and lower accuracy than the congruent [udz], whereas there was no difference between the congruent [uts] and the incongruent [utz]. This finding was replicated across different places of articulation as well; Hwang et al. (2010) argued that [voice] must be a privative feature in English and that listeners use [voice] to construct expectations about what they will hear next. This is why [uds], which violates the expectation, elicited the slowest reaction times and lowest accuracy, whereas [udz], which is consistent with predicting [voice], elicited the fastest reaction times and highest accuracy. The responses to both [uts] and [utz], the latter of which is never attested in English (Smith 1997), fall in between the voiced cases. Hwang et al. (2010) interpreted this finding as suggesting that $[\mathrm{t}]$ is underspecified for [voice] and therefore cannot serve as the basis for predictions.

Finally, a largely recent series of EEG and MEG MMN studies have tested whether asymmetric findings are also observable in the brain. In particular, standards 
that contain privative features elicit larger MMN responses than underspecified standards. The logic is that if the standard is specified for a given feature, then sensory memory constructs a representation of the standard specified with the given feature. This representation is then used to predict each subsequent stimulus. When presented with a deviant that is underspecified for the given feature, a mismatch is encountered. When the standard is underspecified and the deviant specified, a no mismatch will occur, resulting in a smaller MMN compared with the mismatch case. Cornell et al. (2013) observed an asymmetric MMN paradigm for the pseudoword pair [edi]/[egi]. A larger MMN was observed when [egi] was the standard and [edi] the deviant, as the surface properties of [d] conflict with the underlying [dorsal] representation of [g]. A smaller MMN was observed in the opposite case, as there are no underlying place features of [d] (i.e., [coronal] is underspecified) with which [g] conflicts. In a follow-up experiment, Cornell et al. (2013) tested the hypothesis that manner of articulation can also be featurally underspecified. Again, they report an asymmetric MMN: a larger MMN was observed when [eni] was the standard (i.e., [nasal] is specified) and [edi] the deviant (i.e., [plosive] is underspecified). A smaller MMN was observed in the opposite direction. Cornell et al. (2013) note that this is arguably the first time that brain-based evidence has been used to weigh in on place- and manner-of-articulation contrasts in consonants.

In related findings, Eulitz and Lahiri (2004) showed that the same was true for [coronal] in German vowels; Scharinger, Monahan and Idsardi (2012) for the feature [mid] in English vowels; Hestvik and Durvasula (2016) for [spread glottis] in English; Schluter et al., (2017) for voicing in English, Russian, and Arabic; and Schluter, Politzer- 
Ahles and Almeida (2016) for place in English fricatives. In recent unpublished research from my laboratory (P.J. Monahan and J. Schertz, manuscript in preparation), we observed that the auditory cortex is able to abstract over two distinct phonetic implementations of "voicing" in English (i.e., VOT in stops and glottal activity in fricatives) to construct a standard representation with a purely abstract phonological feature that groups all voiced segments together and all voiceless segments together. As in the Hestvik and Durvasula (2016) and Schluter et al., (2017) cases mentioned above, a voiceless standard results in a larger MMN than a voiced standard. Binary, or equipollent, feature valuations would predict symmetrical MMN responses in the above cases. That is, there should be no qualitative difference between positive and negative feature valuations in terms of the construction of standard representations in an MMN paradigm. Monovalent, or privative, feature systems, however, make such asymmetrical predictions (Lahiri \& Reetz 2010). As such, the body of MMN research to date favors such monovalent or privative feature systems.

\section{Identifying Predictions Before the Stimulus}

Section 3 describes an approach to the problem of speech comprehension in which phonological features play a role in a predictive, Analysis-by-Synthesis system. Direct evidence for such predictions during speech comprehension tasks, however, remain limited. Poeppel and Monahan (2011) provide findings from audio-visual speech perception tasks and a handful of behavioral and neurophysiological results using auditory-only materials that indicate that the speech comprehension system invokes predictive mechanisms (see Section 6). The results, however, are far from conclusive or overwhelming. Moreover, in the discussion of predictions, one key aspect is often 
omitted. Specifically, if our perceptual system or the brain is engaging in predictive behavior, we should observe evidence for these predictions prior to the signal that is being predicted. That is, the temporal component is often overlooked in these findings. Instead, the presence of some regularity violation on the predicted signal is often what is reported (Flagg et al. 2006, Hwang et al. 2010, van Wassenhove et al. 2005). In neurophysiological studies, disentangling the predictive response to the signal being predicted from responses to the context that serves as the source of the prediction (as well as other acoustic cues within the stimulus itself) is quite difficult. In this section, I report a recent set of results that indicate an initial, yet promising first step in better identifying the nature of these predictive mechanisms and the role that relatively abstract phonological knowledge plays in their generation. In particular, evidence for predictions prior to the predicted signal has been observed, and moreover, these predictions are based on relatively abstract phonological properties of the segments used in the experiment.

The MMN is typically defined as a neurophysiological change detector, an error detection mechanism that indexes when a deviant stimulus conflicts with the memory trace of the standard stimulus along some perceptual or representational dimension (Näätänen 2001, Näätänen et al. 2005, 2007). It is easy to also conceptualize this process as one of prediction (see Winkler 2007 for a similar perspective). That is, each successive presentation of the standard token during an oddball paradigm is predicted, and the MMN occurs as a violation of this prediction. Although error detection mechanisms are a hallmark of predictive systems (Guenther \& Vladusich 2012, Hickok 2012, Tian \& Poeppel 2010), when the result of interest is the response to the predicted 
stimulus itself, it is difficult to determine whether an active prediction process was invoked by the perceptual system or whether the perceptual system was simply reacting to a violation. What is needed then, is evidence that predictions are made prior to the presentation of the predicted stimulus.

Ascribing functional roles to various rhythms in neuronal activity has proven to be particularly powerful in explaining the cortical mechanisms that underlie sensory perception and cognitive processing (Buzsaki 2004, Mazaheri et al. 2014), and especially speech and language processing (Arnal \& Giraud 2012, Arnal et al. 2011, Doelling et al. 2014, Morillon \& Schroeder 2015, Obleser \& Weisz 2012). Studies have shown that $\beta$-frequencies $(15-30 \mathrm{~Hz})$ were dominant in propagating information flow in a top-down manner, whereas $\gamma$-frequencies $(30-80 \mathrm{~Hz})$ were dominant in propagating bottom-up information flow (Fontolan et al. 2014). This functional separation of frequency channels aligns with assumptions about the predictive coding framework (Friston 2005): Prediction errors stem from bottom-up sensory evidence, and predictions stem from representational units being projected top-down (Arnal \& Giraud 2012, Wang 2010).

Scharinger, Monahan and Idsardi (2016), replicated their earlier findings (Scharinger et al., 2012), demonstrating that asymmetric amplitudes in the MMN response depended on whether the deviant stimulus was embedded in a series of specified or underspecified standards. Their test of interest was whether mid-vowels are underspecified for height. In particular, the underspecified deviant $[\varepsilon]$ elicited a larger MMN response when embedded in a series of height-specified [I] vowels versus when the specified deviant [I] was embedded in a series of underspecified standard $[\varepsilon]$ 
tokens. No such asymmetry was observed when both vowel categories had a height specification (i.e., [I] and [æ]). This analysis, however, does not differ from simple violation detection in its ability to dissociate active predictions. In a subsequent power analysis of the MEG response, Scharinger et al. (2016) observed $\beta$-frequency power reduction when comparing the predictive versus nonpredictive standards in the prestimulus baseline (see Figure 3B).

\section{INSERT FIGURE 3 ABOUT HERE}

This finding is consistent with previous evidence of top-down information propagation observed in prestimulus intervals (Bastos et al. 2015) and in the activation of higherlevel linguistic representations during language comprehension (Molinaro et al. 2016). This prestimulus neural activity is a hallmark of predictive coding mechanisms, and importantly here, Scharinger et al., (2016) are demonstrating an instance of what cortical hypothesis generation is (Doelling et al. 2014). That is, specific, abstract characteristics of the speech sound representation are being predicted. This research is, to my knowledge, the first to demonstrate that these neural mechanisms may be based on specific representational properties of speech sounds and that the perceptual system utilizes these features as a basis for generating guesses about what it is likely to hear next. And crucially, these predictions are observable prior to stimulation.

Another recent finding that highlights prestimulus sensitivity is that of Leonard et al., (2016), discussed above. Although this study did not focus on the role of distinctive features per se, it provides additional support for the idea that we should be able to 
observe predictive and bias effects prior to hearing the relevant phonetic/phonological information. In a follow-up analysis of their ECoG data, Leonard et al., (2016) performed a principal components analysis of the activity across electrodes and time and observed perceptual bias effects approximately $130 \mathrm{~ms}$ prior to the critical phoneme (noise) on noise trials. These prestimulus bias effects again localized to bilateral STG and MTG.

\section{Outstanding Issues and Future Directions}

We are only beginning to understand the role that phonological distinctive features play in the range of various architectures, both perceptual and neurobiological, that would support feature representations. Initial findings appear to support their relevance during speech comprehension and to demonstrate that, crucially, they serve as a basis for generating guesses in a predictive framework. Unfortunately, a number of challenges must still be overcome. First, the evidence for features and predictions in phonological contexts is not yet well established. Although the findings present in the literature appear to be robust, for only a handful of these findings is a feature-based account offered and favored over a segmental or syllabic one. Second, the range of tasks and paradigms that have shown evidence for features and predictions is limited. Although some behavioral findings do exist (see Sections 2 and 6), within the EEG/MEG literature, the bulk arise from MMN paradigms. MMN paradigms are incredibly powerful and useful, but a broader array of methods should be utilized. A particular concern is that these studies are typically performed on segments in isolation or on CV/VCV syllables at most. Scaling up to larger chunks of speech (e.g., multisyllabic sequences, words, sentences), is a nontrivial task for auditory MMN paradigms. Thus, the ecological 
validity of such predictive mechanisms in more naturalistic settings is far from obvious. Moreover, some existing studies failed to find asymmetric MMN responses when they would be expected (Bonte et al. 2005, Mitterer 2003). Bonte et al., (2005) offer a prototypicality/frequency explanation for asymmetric MMN responses. Although it is unclear whether such an account would explain the range of findings in the literature, more research is certainly needed to discern these two hypotheses. Finally, more computationally explicit models of perception with features at the center are necessary. Currently, the available computationally implemented models are relatively agnostic with regard to their assumptions about features.

\section{Conclusion}

This review has presented an array of findings, with three goals. First, it has been established that relatively abstract phonological distinctive features play some role in speech comprehension, which has been observed in both behavioral and neurophysiological studies. Second, relatively abstract properties of features---that is, whether the feature is privative and specified or not---appear to serve as a basis for predictions during speech perception, consistent with models that invoke prediction as a core mechanism in speech comprehension. This perspective is also compatible with models that incorporate only abstract representations or those that combine both abstract representations with indexical phonetic detail, which attempt to account for talker-specific processing effects (Pierrehumbert 2016). Finally, linking linguistic concepts and constructs with neurobiology (or even cognitive psychology) has not been an obvious endeavor (Poeppel 2012), which is unfortunate if the representations, 
processes, and mechanisms proposed by linguists, and phonologists in particular, are to have some mental instantiation. Although much remains unknown, the linking of features with perception and neurobiology is arguably the most tractable avenue currently available. This approach may enable us to use linguistic theories to make predictions about behavior and the brain, and ideally, behavior and the brain should help us inform our linguistic theories. In short, access to our phonological knowledge and these predictive mechanisms helps listeners achieve the seemingly impossible task of speech comprehension so effortlessly. 


\section{Literature Cited}

Altmann CF, Uesaki M, Ono K, Matsuhashi M, Mima T, Fukuyama H. 2014. Categorical speech perception during active discrimination of consonants and vowels.

Neuropsychologia. 64(C):13-23

Archangeli D. 1988. Aspects of underspecification theory. Phonology. 5(2):183-207

Arnal LH, Giraud A-L. 2012. Cortical oscillations and sensory predictions. Trends in Cognitive Sciences. 16(7):390-98

Arnal LH, Wyart V, Giraud A-L. 2011. Transitions in neural oscillations reflect prediction errors generated in audiovisual speech. Nature Neurosci. 14(6):797-801

Arsenault JS, Buchsbaum BR. 2015. Distributed Neural Representations of Phonological Features during Speech Perception. J Neurosci. 35(2):634-42

Astikainen P, Lillstrang E, Ruusuvirta T. 2008. Visual mismatch negativity for changes in orientation - a sensory memory-dependent response. Euro J Neurosci. 28(11):2319-24

Atienza M, Cantero JL, Dominguez-Marin E. 2002. Mismatch negativity (MMN): An objective measure of sensory memory and long-lasting memories during sleep. Int $J$ Psychophysiol. 46(3):215-25

Avery P, Rice K. 1989. Segment Structure and Coronal Underspecification. Phonology. 6(2):179-200

Bar M. 2007. The proactive brain: using analogies and associations to generate predictions. Trends in Cognitive Sciences. 11(7):280-89

Bar M. 2009a. Predictions: a universal principle in the operation of the human brain. Phil Trans $R$ Soc B. 364(1521):1181-82

Bar M. 2009b. The proactive brain: memory for predictions. Phil Trans $R$ Soc $B$. 364(1521):1235-43

Bar M, Kassam KS, Ghuman AS, Boshyan J, Schmidt AM, et al. 2006. Top-down facilitation of visual recognition. $P$ Natl Acad Sci Usa. 103(2):449-54

Bastos AM, Vezoli J, Bosman CA, Schoffelen J-M, Oostenveld R, et al. 2015. Visual Areas Exert Feedforward and Feedback Influences through Distinct Frequency Channels. Neuron. 85(2):390-401

Beckman ME, Pierrehumbert J. 2004. Interpreting "phonetic interpretation" over the lexicon. Papers in laboratory phonology VI. 13-38

Berent I. 2013. The Phonological Mind. Cambridge, UK: Cambridge Univ Press

Best CT, Strange W. 1992. Effects of phonological and phonetic factors on crosslanguage perception of approximants. J Phonetics. 20(3):305-30

Bever TG, Poeppel D. 2010. Analysis by synthesis: A (re-) emerging program of research for language and vision. Bioling. 4(2-3):174-200

Blumstein SE, Stevens KN. 1979. Acoustic invariance in speech production: Evidence from measurements of the spectral characteristics of stop consonants. $J$ Acoust Soc Am. 66(4):1001-17

Blumstein SE, Stevens KN. 1980. Perceptual invariance and onset spectra for stop consonants in different vowel environments. J Acoust Soc Am. 67(2):648-62

Bonte M, Mitterer H, Zellagui N, Poelmans H, Blomert L. 2005. Auditory cortical tuning 
to statistical regularities in phonology. Clinical Neurophysiology. 116(12):2765-74 Brentari D. 2011. Sign Language Phonology. In The Handbook of Phonological Theory, eds. JA Goldsmith, J Riggle, ACL Yu, pp. 691-721. Oxford, UK: Wiley-Blackwell. 2nd ed.

Browman CP, Goldstein L. 1989. Articulatory gestures as phonological units. Phonology. 6(2):201-51

Buzsaki G. 2004. Neuronal Oscillations in Cortical Networks. Science. 304(5679):192629

Carbonell KM, Lotto AJ. 2014. Speech is not special... again. Frontiers in Psychology. 5(203):427

Chang EF, Rieger JW, Johnson K, Berger MS, Barbaro NM, Knight RT. 2010.

Categorical speech representation in human superior temporal gyrus. Nature Neurosci. 13(11):1428-32

Chomsky N, Halle M. 1968. The Sound Pattern of English. Cambridge, MA: MIT Press Clements GN. 1985. The Geometry of Phonological Features. Phonology Yearbook. 2:225-52

Coleman J. 1998. Cognitive reality and the phonological lexicon: A review. J Neuroling. 11(3):295-320

Coleman J. 2003. Discovering the acoustic correlates of phonological contrasts. $J$ Phonetics. 31(3-4):351-72

Cooper FS, Liberman AM, Delattre PC, Borst JM, Gerstman LJ. 1952. Some Experiments on the Perception of Synthetic Speech Sounds. J Acoust Soc Am. 24(6):597-606

Cornell SA, Lahiri A, Eulitz C. 2013. Inequality across consonantal contrasts in speech perception: evidence from mismatch negativity. J Exp Psychol Human Percept Perform. 39(3):757-72

Correia JM, Jansma BMB, Bonte M. 2015. Decoding Articulatory Features from fMRI Responses in Dorsal Speech Regions. J Neurosci. 35(45):15015-25

Csépe V, Karmos G, Molnár M. 1987. Evoked-Potential Correlates of Stimulus Deviance During Wakefulness and Sleep in Cat - Animal-Model of Mismatch Negativity. Electroenceph Clin Neurophys. 66(6):571-78

Csépe V, Pallier C, Hoke M, Hampson S, Ross B. 1992. Evoked magnetic responses of the human auditory cortex to minor pitch changes: localization of the mismatch field. Electroenceph Clin Neurophys. 84(6):538-48

Dell GS, Juliano C, Govindjee A. 1993. Structure and Content in Language Production: A Theory of Frame Constraints in Phonological Speech Errors. Cognitive Science. 17(2):149-95

Diehl RL, Lotto AJ, Holt LL. 2004. Speech perception. Annu. Rev. Psychol. 55:149-79

Doelling KB, Arnal LH, Ghitza O, Poeppel D. 2014. Acoustic landmarks drive deltatheta oscillations to enable speech comprehension by facilitating perceptual parsing. Neurolmage. 85(P2):761-68

Dresher BE. 2015a. The arch not the stones: Universal feature theory without universal features. Nordlyd. 41(2):165-81

Dresher BE. 2015b. The motivation for contrastive feature hierarchies in phonology. 
Linguistic Variation. 15(1):1-40

Dressler WU. 1984. Explaining natural phonology. Phonology. 19(1):577-621

Eimas PD, Corbit JD. 1973. Selective adaptation of linguistic feature detectors. Cogn Psychol. 4(1):99-109

Ettinger A, Linzen T, Marantz A. 2014. The role of morphology in phoneme prediction: Evidence from MEG. Brain Lang. 129(C):14-23

Eulitz C, Lahiri A. 2004. Neurobiological evidence for abstract phonological representations in the mental lexicon during speech recognition. $J$ Cognitive Neurosci. 16(4):577-83

Federmeier KD. 2007. Thinking ahead: The role and roots of prediction in language comprehension. Psychophysiology. 44(4):491-505

Fischer C, Morlet D, Giard MH. 2000. Mismatch negativity and N100 in comatose patients. Audiol Neurootol. 5(3-4):192-97

Flagg EJ, Oram Cardy JE, Roberts TPL. 2006. MEG detects neural consequences of anomalous nasalization in vowel-consonant pairs. Neurosci. Lett. 397(3):263-68

Fontolan L, Morillon B, Liegeois-Chauvel C. 2014. The contribution of frequency-specific activity to hierarchical information processing in the human auditory cortex. Nature. 5:4694

Fowler CA. 1996. Listeners do hear sounds, not tongues. J Acoust Soc Am. 99(3):1730-41

Friston K. 2005. A Theory of Cortical Responses. Philosophical Transactions: Biological Sciences. 360(1456):815-36

Gage NM, Poeppel D, Roberts TPL, Hickok GS. 1998. Auditory evoked M100 reflects onset acoustics of speech sounds. Brain Res. 814(1-2):236-39

Galantucci B, Fowler CA, Turvey MT. 2006. The motor theory of speech perception reviewed. Psychon Bull Rev. 13(3):361-77

Gaskell MG, Marslen-Wilson WD. 1996. Phonological variation and inference in lexical access. J Exp Psychol Human Percept Perform. 22(1):144-58

Gay T. 1968. Effect of speaking rate on diphthong formant movements. J Acoust Soc Am. 44(6):1570-73

Geschwind N. 1970. The organization of language and the brain. Science. 170(3961):940-44

Gick B, Derrick D. 2009. Aero-tactile integration in speech perception. Nature. 462(7272):502-4

Goldinger SD. 1996. Words and voices: episodic traces in spoken word identification and recognition memory. J Exp Psychol Learn Mem Cogn. 22(5):1166-83

Goldinger SD, Azuma T. 2003. Puzzle-solving science: the quixotic quest for units in speech perception. J Phonetics. 31(3-4):305-20

Gomes H, Ritter W, Vaughan HG. 1995. The nature of preattentive storage in the auditory system. J Cognitive Neurosci. 7(1):81-94

Gow DW Jr. 2003. Feature parsing: Feature cue mapping in spoken word recognition. Attn Perc Psychophys. 65(4):575-90

Gow DW Jr., Im AM. 2004. A cross-linguistic examination of assimilation context effects. J Mem Lang. 51(2):279-96 
Grossberg S. 1999. Speaking in shorthand-A syllable-centric perspective for understanding pronunciation variation. Speech Comm. 29(2):159-76

Guenther FH, Vladusich T. 2012. A Neural Theory of Speech Acquisition and Production. J Neuroling. 25(5):408-22

Hagoort P, Hald L, Bastiaansen M, Petersson KM. 2004. Integration of word meaning and world knowledge in language comprehension. Science. 304(5669):438-41

Hale M, Reiss C. 2008. The phonological enterprise

Halle M. 2002. From Memory to Speech and Back. Berlin: Walter de Gruyter

Halle M, Clements GN. 1983. Problem book in phonology. Cambridge, Mass

Halle M, Stevens KN. 1962. Speech recognition: A model and a program for research. IRE Transactions on Information Theory. 8(2):155-59

Hari R, Rif J, Tiihonen J, Sams M. 1992. Neuromagnetic Mismatch Fields to Single and Paired Tones. Electroenceph Clin Neurophys. 82(2):152-54

Harris J, Lindsey G. 2002. The elements of phonological representation. In Frontiers in Phonology, eds. J Durand, F Katamba, pp. 37-49. Essex

Hestvik A, Durvasula K. 2016. Neurobiological evidence for voicing underspecification in English. Brain Lang. 152(C):28-43

Hickok GS. 2012. Computational neuroanatomy of speech production. Nat Rev Neurosci. 13(2):135-45

Hickok GS. 2014. The architecture of speech production and the role of the phoneme in speech processing. Language and Cognitive Processes. 29(1):2-20

Hickok GS, Poeppel D. 2007. The cortical organization of speech processing. Nat Rev Neurosci. 8(5):393-402

Hockett CF. 1960. The Origin of Speech. Scientific American. 203(3):88-96

Holt LL, Lotto AJ. 2008. Speech Perception Within an Auditory Cognitive Science

Framework. Curr Dir Psychol Sci. 17(1):42-46

Hwang S-OK, Monahan PJ, Idsardi WJ. 2010. Underspecification and asymmetries in voicing perception. Phonology. 27(2):205-24

Idsardi WJ, Monahan PJ. 2016. Phonology. In Neurobiology of Language, eds. GS Hickok, SL Small, pp. 141-51. Amsterdam: Elsevier Science

Idsardi WJ, Poeppel D. 2012. Neurophysiological techniques in laboratory phonology. In The Oxford Handbook of Laboratory Phonology, eds. AC Cohn, C Fougeron, MK Huffman, pp. 593-605. Oxford: Oxford University Press

Jakobson R, Fant CGF, Halle M. 1961. Preliminaries to Speech Analysis. Cambridge, MA: MIT Press

Johnson K. 1997. Speech Perception Without Speaker Normalization. In Talker

Variability in Speech Processing, eds. K Johnson, JW Mullennix, pp. 145-65. San

Diego, CA: Academic Press

Johnson K, Babel M. 2010. On the perceptual basis of distinctive features: Evidence from the perception of fricatives by Dutch and English speakers. $J$ Phonetics. 38(1):127-36

Jusczyk PW, Luce PA. 2002. Speech perception and spoken word recognition: past and present. Ear Hear. 23(1):2-40

Kandylaki KD, Nagels A, Tune S, Kircher T, Wiese R, et al. 2016. Predicting "When" in 
Discourse Engages the Human Dorsal Auditory Stream: An fMRI Study Using Naturalistic Stories. J Neurosci. 36(48):12180-91

Katz JJ, Fodor JA. 1963. The Structure of a Semantic Theory. Lang. 39(2):170

Kazanina N, Phillips C, Idsardi WJ. 2006. The influence of meaning on the perception of speech sounds. P Natl Acad Sci Usa. 103(30):11381-86

Kimberley TJ, Lewis SM. 2007. Understanding neuroimaging. Phys Ther. 87(6):670-83

Klatt DH. 1989. Review of selected models of speech perception. In Lexical

Representation and Process, ed. WD Marslen-Wilson, pp. 169-226. Cambridge, MA: The MIT Press

Kraljic T, Samuel AG. 2006. Generalization in perceptual learning for speech. Psychon Bull Rev. 13(2):262-68

Kraljic T, Samuel AG. 2011. Perceptual learning evidence for contextually-specific representations. Cognition. 121(3):459-65

Kuperberg GR, Jaeger TF. 2016. What do we mean by prediction in language comprehension? Language, Cognition and Neuroscience. 31(1):32-59

Kutas M, Hillyard SA. 1980. Reading Senseless Sentences - Brain Potentials Reflect Semantic Incongruity. Science. 207(4427):203-5

Lahiri A, Marslen-Wilson WD. 1991. The mental representation of lexical form: a phonological approach to the recognition lexicon. Cognition. 38(3):245-94

Lahiri A, Reetz H. 2002. Underspecified recognition. Lab Phon. 7:637-76

Lahiri A, Reetz H. 2010. Distinctive features: Phonological underspecification in representation and processing. $J$ Phonetics. 38(1):44-59

Lau EF, Phillips C, Poeppel D. 2008. A cortical network for semantics: (de)constructing the N400. Nat Rev Neurosci. 9(12):920-33

Lawyer L, Corina D. 2014. An investigation of place and voice features using fMRIadaptation. J Neuroling. 27(1):18-30

Leonard MK, Baud MO, Sjerps MJ, Chang EF. 2016. Perceptual restoration of masked speech in human cortex. Nature Comm. 7:1-9

Leonard MK, Chang EF. 2014. Dynamic speech representations in the human temporal lobe. Trends in Cognitive Sciences. 1-8

Levelt WJ, Roelofs A, Meyer AS. 1999. A theory of lexical access in speech production. Behav Brain Sci. 22(1):1-75

Liberman AM. 1996. Speech. Cambridge, MA: MIT Press

Liberman AM, Cooper FS, Shankweiler D, Studdert-Kennedy M. 1967. Perception of the speech code. Psychol Rev. 74(6):431-61

Liberman AM, Fry DB, Abramson AS, Eimas PD. 1962. The identification and discrimination of synthetic vowels. Language and Speech. 5(4):171-89

Liberman AM, Harris KS, Hoffman HS, Griffith BC. 1957. The discrimination of speech sounds within and across phoneme boundaries. J Exp Psychol. 54(5):358-68

Liberman AM, Harris KS, Kinney JA, Lane H. 1961. The discrimination of relative onsettime of the components of certain speech and nonspeech patterns. J Exp Psychol. 61:379-88

Liberman AM, Mattingly IG. 1985. The motor theory of speech perception revised. Cognition. 21(1):1-36 
Liberman AM, Mattingly IG. 1989. A Specialization for Speech-Perception. Science. 243(4890):489-94

Lindblom B. 1992. Phonological units as adaptive emergents of lexical development. In Phonological Development Models, Research, Implications, eds. CA Ferguson, L Menn, C Stoel-Gammon, pp. 131-63. Timonium, MD: Phonological development: Models, research, implications

Lombardi L. 1991. Laryngeal Features and Laryngeal Neutralization. University of Massachusetts, Amherst

Lotto AJ, Hickok GS, Holt LL. 2009. Reflections on mirror neurons and speech perception. Trends in Cognitive Sciences. 13(3):110-14

Luck SJ. 2014. An Introduction to the Event-Related Potential Technique. Cambridge, MA: MIT Press. Second ed.

MacKain KS, Best CT, Strange W. 1981. Categorical perception of English /r/ and /// by Japanese bilinguals. Applied Psycholinguistics. 2(04):369-90

Maess B, Mamashli F, Obleser J, Helle L, Friederici AD. 2016. Prediction Signatures in the Brain: Semantic Pre-Activation during Language Comprehension. Frontiers in Human Neuroscience. 10:280-11

Marslen-Wilson WD. 1987. Functional parallelism in spoken word-recognition. Cognition. 25(1-2):71-102

Mazaheri A, van Schouwenburg MR, Dimitrijevic A, Denys D, Cools R, Jensen O. 2014. Region-specific modulations in oscillatory alpha activity serve to facilitate processing in the visual and auditory modalities. Neurolmage. 87:356-62

McCarthy JJ. 1988. Feature Geometry and Dependency: A Review. Phonetica. 45(24):84-108

McClelland JL, Elman JL. 1986. The TRACE model of speech perception. Cogn Psychol. 18(1):1-86

McGurk H, MacDonald J. 1976. Hearing Lips and Seeing Voices. Nature. 264(5588):746-48

McMurray B, Aslin RN, Tanenhaus MK, Spivey MJ, Subik D. 2008. Gradient sensitivity to within-category variation in words and syllables. J Exp Psychol Human Percept Perform. 34(6):1609-31

McMurray B, Tanenhaus MK, Aslin RN. 2002. Gradient effects of within-category phonetic variation on lexical access. Cognition. 86(2):B33-B42

McQueen JM, Cutler A, Norris D. 2006. Phonological Abstraction in the Mental Lexicon. Cognitive Science. 30(6):1113-26

Mesgarani N, Cheung C, Johnson K, Chang EF. 2014. Phonetic Feature Encoding in Human Superior Temporal Gyrus. Science. 343(6174):1006-10

Mester RA, Itô J. 1989. Feature Predictability and Underspecification: Palatal Prosody in Japanese Mimetics. Lang. 65(2):258-93

Mielke J. 2008. The Emergence of Distinctive Features. Oxford: Oxford University Press Miller GA, Nicely PE. 1955. An analysis of perceptual confusions among some English consonants. J Acoust Soc Am. 27(2):338-52

Miller JD. 1989. Auditory-perceptual interpretation of the vowel. J Acoust Soc Am. 85(5):2114-34 
Miller JL, Volatis LE. 1989. Effect of Speaking Rate on the Perceptual Structure of a Phonetic Category. Percept Psychophys. 46(6):505-12

Mitterer H. 2003. Understanding "gardem bench": Studies on the perception of assimilation word forms [dissertation]. Universiteit Maastricht, Maastricht, The Netherlands

Mitterer H. 2007. Behavior reflects the (degree of) reality of phonological features in the brain as well. ICPhS. 16:127-30

Mohanan KP. 1991. On the Bases of Radical Underspecification. Natural Language \& Linguistic Theory. 9(2):285-325

Moisik SR, Gick B. 2017. The Quantal Larynx: The Stable Regions of Laryngeal Biomechanics and Implications for Speech Production. J. Speech Lang. Hear. Res. 60(3):540-21

Molinaro N, Monsalve IF, Lizarazu M. 2016. Is there a common oscillatory brain mechanism for producing and predicting language? Lang. 31(1):145-58

Monahan PJ, Idsardi WJ. 2010. Auditory sensitivity to formant ratios: Toward an account of vowel normalisation. Language and Cognitive Processes. 25(6):808-39

Monahan PJ, Lau EF, Idsardi WJ. 2013. Computational primitives in phonology and their neural correlates. In The Cambridge Handbook of Biolinguistics, eds. C Boeckx, KK Grohmann, pp. 233-56. Cambridge: Cambridge University Press

Morillon B, Schroeder CE. 2015. Neuronal oscillations as a mechanistic substrate of auditory temporal prediction. Ann. N.Y. Acad. Sci. 1337(1):26-31

Mowrey RA, MacKay IRA. 1990. Phonological primitives: Electromyographic speech error evidence. J Acoust Soc Am. 88(3):1299-1312

Nashida T, Yabe H, Sato Y, Hiruma T, Sutoh T, et al. 2000. Automatic auditory information processing in sleep. Sleep. 23(6):821-28

Näätänen R. 2001. The perception of speech sounds by the human brain as reflected by the mismatch negativity (MMN) and its magnetic equivalent (MMNm).

Psychophysiology. 38(1):1-21

Näätänen R, Jacobsen T, Winkler I. 2005. Memory-based or afferent processes in mismatch negativity (MMN): A review of the evidence. Psychophysiology. 42(1):2532

Näätänen R, Kreegipuu K. 2012. The Mismatch Negativity (MMN). In The Oxford Handbook of Event-Related Potential Components, ed. ES Kappenman, pp. 14358. Oxford, UK: Oxford University Press

Näätänen R, Lehtokoski A, Lennes M, Cheour M, Huotilainen M, et al. 1997. Languagespecific phoneme representations revealed by electric and magnetic brain responses. Nature. 385(6615):432-34

Näätänen R, Paavilainen P, Rinne T, Alho K. 2007. The mismatch negativity (MMN) in basic research of central auditory processing: A review. Clinical Neurophysiology. 118(12):2544-90

Näätänen R, Winkler I. 1999. The concept of auditory stimulus representation in cognitive neuroscience. Psychol Bull. 125(6):826-59

Norris D. 1994. Shortlist: A connectionist model of continuous speech recognition. Cognition. 52(3):189-234 
Norris D, McQueen JM. 2008. Shortlist B: A Bayesian model of continuous speech recognition. Psychol Rev. 115(2):357-95

Norris D, McQueen JM, Cutler A. 2000. Merging information in speech recognition: Feedback is never necessary. Behav Brain Sci. 23(3):299-325

Obleser J, Eisner F. 2009. Pre-lexical abstraction of speech in the auditory cortex. Trends in Cognitive Sciences. 13(1):14-19

Obleser J, Lahiri A, Eulitz C. 2003. Auditory-evoked magnetic field codes place of articulation in timing and topography around 100 milliseconds post syllable onset. Neurolmage. 20(3):1839-47

Obleser J, Lahiri A, Eulitz C. 2004. Magnetic brain response mirrors extraction of phonological features from spoken vowels. J Cognitive Neurosci. 16(1):31-39

Obleser J, Weisz N. 2012. Suppressed alpha oscillations predict intelligibility of speech and its acoustic details. Cereb Cortex. 22(11):2466-77

Penfield W, Roberts L. 1959. Speech and Brain Mechanisms, Vol. Princeton, NJ. Princeton University Press

Peterson GE, Barney HL. 1952. Control Methods Used in a Study of the Vowels. $J$ Acoust Soc Am. 24(2):175-84

Phillips C. 2001. Levels of representation in the electrophysiology of speech perception. Cognitive Science. 25(5):711-31

Phillips C, Pellathy T, Marantz A, Yellin E, Wexler K, et al. 2000. Auditory cortex accesses phonological categories: an MEG mismatch study. J Cognitive Neurosci. 12(6): 1038-55

Picton TW. 2011. Human Auditory Evoked Potentials. San Diego, CA: Plural Publishing

Pierrehumbert JB. 2003. Phonetic diversity, statistical learning, and acquisition of phonology. Language and Speech. 46(Pt 2-3):115-54

Pierrehumbert JB. 2016. Phonological representation: Beyond abstract versus episodic. Ann Rev Ling. 2: 33-52

Poeppel D. 2003. The analysis of speech in different temporal integration windows: cerebral lateralization as "asymmetric sampling in time." Speech Comm. 41(1):24555

Poeppel D. 2012. The maps problem and the mapping problem: Two challenges for a cognitive neuroscience of speech and language. Cognitive Neuropsychology. 29(12):34-55

Poeppel D, Idsardi WJ, van Wassenhove V. 2008. Speech perception at the interface of neurobiology and linguistics. Phil Trans $R$ Soc B. 363(1493):1071-86

Poeppel D, Monahan PJ. 2011. Feedforward and feedback in speech perception: Revisiting analysis by synthesis. Language and Cognitive Processes. 26(7):935-51

Port RF, Leary AP. 2005. Against Formal Phonology. Lang. 81(4):927-64

Potter RK, Steinberg JC. 1950. Toward the Specification of Speech. J Acoust Soc Am. 22(6):807-20

Prince A, Smolensky P. 2004. Optimality Theory: Constraint Interaction in Generative Grammar. Malden, MA: Wiley-Blackwell

Rao RP, Ballard DH. 1999. Predictive coding in the visual cortex: a functional interpretation of some extra-classical receptive-field effects. Nature Neurosci. 


\section{2(1):79-87}

Reiss C. 2017. Substance free phonology. In Handbook of Phonological Theory, eds. SJ Hannahs, A Bosch. Handbook of phonological theory

Rivera-Gaxiola M, Silva-Pereyra J, Kuhl PK. 2005. Brain potentials to native and nonnative speech contrasts in 7- and 11-month-old American infants. Dev Sci. 8(2):162-72

Roberts TPL, Ferrari P, Stufflebeam SM, Poeppel D. 2000. Latency of the auditory evoked neuromagnetic field components: stimulus dependence and insights toward perception. J Clin Neurophys. 17(2):114

Roberts TPL, Flagg EJ, Gage NM. 2004. Vowel categorization induces departure of M100 latency from acoustic prediction. NeuroReport. 15(10):1679-82

Roelofs A. 1999. Phonological Segments and Features as Planning Units in Speech Production. Language and Cognitive Processes. 14(2):173-200

Sabri M, Radnovich AJ, Li TQ, Kareken DA. 2005. Neural correlates of olfactory change detection. Neurolmage. 25(3):969-74

Sagey E. 1986. The representation of features and relations in autosegmental phonology. Doctoral dissertation, MIT, Cambridge, Massachusetts

Sams M, Kaukoranta E, Hämäläinen M, Näätänen R. 1991. Cortical Activity Elicited by Changes in Auditory-Stimuli: Different Sources for the Magnetic N100m and Mismatch Responses. Psychophysiology. 28(1):21-29

Samuel AG. 2011. Speech Perception. Annu. Rev. Psychol. 62(1):49-72

Scharinger M, Idsardi WJ, Poe S. 2011. A comprehensive three-dimensional cortical map of vowel space. J Cognitive Neurosci. 23(12):3972-82

Scharinger M, Monahan PJ, Idsardi WJ. 2016. Linguistic category structure influences early auditory processing: Converging evidence from mismatch responses and cortical oscillations. Neurolmage. 128:293-301

Scharinger M, Monahan PJ, Idsardi WJ. 2012. Asymmetries in the Processing of Vowel Height. J. Speech Lang. Hear. Res. 55(3):903-18

Schluter K, Politzer-Ahles S, Almeida D. 2016. No place for /h/: an ERP investigation of English fricative place features. Language, Cognition and Neuroscience. 31(6):72840

Schluter K, Politzer-Ahles S, Kaabi Al M, Almeida D. 2017. Laryngeal Features are Phonetically Abstract: Mismatch Negativity Evidence from Arabic, English, and Russian. Frontiers in Psychology 8:746

Schuberth RE, Eimas PD. 1977. Effects of context on the classification of words and nonwords. J Exp Psychol Human Percept Perform. 3(1):27-36

Sculthorpe LD, Ouellet DR, Campbell KB. 2009. MMN elicitation during natural sleep to violations of an auditory pattern. Brain Res. 1290:52-62

Sharma A, Dorman MF. 2000. Neurophysiologic correlates of cross-language phonetic perception. J Acoust Soc Am. 107(5):2697-2703

Smith CL. 1997. The devoicing of/z/in American English: effects of local and prosodic context. J Phonetics. 25(4):471-500

Soli SD, Arabie P. 1979. Auditory versus phonetic accounts of observed confusions between consonant phonemes. J Acoust Soc Am. 66(1):46-59 
Steriade D. 2005. Underspecification and Markedness. In The Handbook of

Phonological Theory, ed. JA Goldsmith, pp. 114-74. Cambridge, MA: Blackwell

Stevens KN. 1989. On the quantal nature of speech. J Phonetics. 17(1):3-45

Stevens KN. 2002. Toward a model for lexical access based on acoustic landmarks and distinctive features. J Acoust Soc Am. 111(4):1872

Stevens KN, Blumstein SE. 1978. Invariant cues for place of articulation in stop consonants. J Acoust Soc Am. 64(5):1358-68

Stevens KN, Halle M. 1967. Remarks on Analysis by Synthesis and Distinctive

Features. In Models for the Perception of Speech and Visual Form, ed. W Wathen-

Dunn, pp. 88-102. Cambridge, MA: MIT Press

Stevens KN, Hanson HM. 2010. Articulatory-Acoustic Relations as the Basis of

Distinctive Contrasts. The Handbook of Phonetic Sciences, Second Edition. 424-53

Stevens KN, Keyser SJ. 2010. Quantal theory, enhancement and overlap. J Phonetics. 38(1):10-19

Studdert-Kennedy M, Shankweiler D. 1970. Hemispheric Specialization for Speech Perception. J Acoust Soc Am. 48(2):579-\&

Studdert-Kennedy M, Shankweiler D, Pisoni D. 1972. Auditory and phonetic processes in speech perception: Evidence from a dichotic study. Cogn Psychol. 3(3):455-66

Sumby WH, Pollack I. 1954. Visual contribution to speech intelligibility in noise. J Acoust Soc Am. 26(2):212

Sussman HM. 2000. Phonemic Representation: A Twenty-First Century Challenge. Brain Lang. 71(1):237-40

Tales A, Newton P, Troscianko T, Butler S. 1999. Mismatch negativity in the visual modality. NeuroReport. 10(16):3363-67

Tian X, Poeppel D. 2010. Mental imagery of speech and movement implicates the dynamics of internal forward models. Frontiers in Psychology. 1:166

Toscano JC, McMurray B, Dennhardt J, Luck SJ. 2010. Continuous Perception and Graded Categorization: Electrophysiological Evidence for a Linear Relationship Between the Acoustic Signal and Perceptual Encoding of Speech. Psychological Science. 21(10):1532-40

Ullman S, Vidal-Naquet M, Sali E. 2002. Visual features of intermediate complexity and their use in classification. Nature Neurosci. 1-6

van der Hulst H. 2016. Monovalent "Features" in Phonology. Language and Linguistics Compass. 10(2):83-102

van Wassenhove V, Grant KW, Poeppel D. 2005. Visual speech speeds up the neural processing of auditory speech. P Natl Acad Sci Usa. 102(4):1181-86

van Wassenhove V, Grant KW, Poeppel D. 2007. Temporal window of integration in auditory-visual speech perception. Neuropsychologia. 45(3):598-607

Vanhaudenhuyse A, Laureys S, Perrin F. 2007. Cognitive Event-Related Potentials in Comatose and Post-Comatose States. Neurocrit Care. 8(2):262-70

Wang MD, Bilger RC. 1973. Consonant confusions in noise: a study of perceptual features. J Acoust Soc Am. 54(5):1248-66

Wang XJ. 2010. Neurophysiological and Computational Principles of Cortical Rhythms in Cognition. Physiological Reviews. 90(3):1195-1268 
Werker JF, Logan JS. 1985. Cross-language evidence for three factors in speech perception. Percept Psychophys. 37(1):35-44

Wijnen VJM, van Boxtel GJM, Eilander HJ, de Gelder B. 2007. Mismatch negativity predicts recovery from the vegetative state. Clinical Neurophysiology. 118(3):597605

Winkler I. 2007. Interpreting the mismatch negativity. Journal of Psychophysiology. 21(3-4):147-63

Winkler I, Lehtokoski A, Alku P, Vainio M, Czigler I, et al. 1999. Pre-attentive detection of vowel contrasts utilizes both phonetic and auditory memory representations. Brain Res Cogn Brain Res. 7(3):357-69

Yuille A, Kersten D. 2006. Vision as Bayesian inference: analysis by synthesis? Trends in Cognitive Sciences. 10(7):301-8 


\section{Acknowledgments}

The writing of this review was supported by Insight Development Grant 430-2015-00647 awarded by the Social Sciences and Humanities Research Council of Canada. I thank an anonymous reviewer for the insightful and constructive criticisms of a previous version of this manuscript.

\section{Disclosure Statement}

The author is not aware of any affiliations, memberships, funding, or financial holdings that might be perceived as affecting the objectivity of this review. 


\section{Acronym and Definitions List}

Electroencephalography (EEG): noninvasive methodology that records electrical voltages from electrodes placed on the scalp, boasting excellent temporal resolution Magnetoencephalography (MEG): noninvasive methodology that records magnetic field potential from superconducting sensor coils, boasting exceling temporal and spatial resolution

Event-related potentials (ERPs)/event-related fields (ERFs): evoked EEG or MEG signals averaged over many repetitions of the presentation of an exogenous stimulus, ERPs in EEG and ERFs in MEG; typically, the amplitude and latency of components in the ERP/ERF waveform are utilized as dependent variables Electrocorticography (ECOG): invasive technique wherein electrode grids are placed directly on the brain surface; offers excellent temporal and spatial resolution but is used only on preoperative patients Mismatch negativity (MMN): negative-going deflection in the ERP elicited via the detection of an oddball "deviant" stimulus in a series of "standard" repeating stimuli 


\section{Sidebar}

\section{Application of Neuroimaging Techniques}

The last 30 years have witnessed substantial innovations in methodologies for observing the functioning human brain in healthy individuals. Previously, scientists interested in the neurological foundations of language were largely limited to the examination of individuals who had experienced lesions or other brain-related deficits (Penfield \& Roberts 1959). Psychological assessments were performed, followed by postmortem examinations. Observed links between psychological deficits and lesion sites represented early attempts to identify the neural substrates of various cognitive faculties, including the language system, and elaborate models were constructed on the basis of these findings with Broca's and Wernicke's areas (Figure 2c) at the center of the language network (see Geschwind 1970 for a review). Current noninvasive methodologies are largely divided into two types: electrophysiological and hemodynamic. Electrophysiological techniques, such as electroencephalography (EEG) and magnetoencephalography (MEG), measure electrical voltage changes across the scalp and their related magnetic field activity, respectively. They boast high temporal resolution but, in the case of EEG, relatively weak spatial resolution. Hemodynamic techniques, such as functional magnetic resonance imaging (fMRI) and positron emission tomography (PET), measure changes in cerebral blood flow and offer high spatial resolution but poor temporal resolution. For an overview of the primary techniques and modes of data collection, see Monahan et al. (2013), Idsardi \& Poeppel (2012), and Kimberley \& Lewis (2007). 


\section{Summary Points list}

1. Putatively abstract properties of our phonological knowledge facilitate and help to constrain our perception of the speech signal.

2. Distinctive features play a role in speech comprehension, serving as a basis for predictions of what we will hear next.

3. Our ability to generate guesses about what we will likely hear next supports our ability to comprehend speech.

4. These predictions are in line with recent models of cognition and perception in adjacent and distinct fields of cognitive science and cognitive neuroscience (vision, sentence comprehension).

5. Investigating the role that features play in behavior and the brain, and using behavior and the brain to understand the nature of distinctive features, serves as a promising link between our models of language and our models of perception and the brain. 
Figure 1. Diagram of the Analysis-by-Synthesis model. Modified from Halle \& Stevens (1962) with permission from IEEE.

**SMALL FIGURE** 
Figure 2 (a) Schematic of a mismatch negativity (MMN) auditory oddball paradigm. A series of standard tokens are auditorily presented and interrupted by the occasional deviant stimulus that differs from the standard along some physical, perceptual, or representational dimension. The evoked brain responses to standard (b/ue) and deviant $(r e d)$ trials are extracted from the continuous electroencephalography (EEG) signal (fronto-central electrode Fz is presented) and averaged together on a condition-bycondition, channel-by-channel basis. (b) Channel locations from a standard 32-channel EEG electrode array and a sample standard and deviant response in an MMN oddball paradigm. The event-related potential (ERP) response to the deviant (red line) and standard (blue line) stimuli at electrode $\mathrm{Fz}$ is provided. The response to the deviant is more negative in the 150--250-ms time window; the difference between the standard and deviant responses is shaded in gray. (c) Some of the principal areas implicated in the neurobiological network for speech perception and spoken word recognition. The unlabeled brain figure in (c) is licensed under the Creative Commons Attribution-Share Alike 4.0 International, 3.0 Unported, 2.5 Generic, 2.0 Generic and 1.0 Generic license.

*LARGE FIGURE* 
Figure 3 (a) Total power distribution for the standard vowels [æ] (left) and [I] (middle) in the specified/large F1 distance comparison. The difference plot (right) indicates no power differences between the standards. Vowels in standard position are underlined in the header lines. Power values are color coded, with warmer colors for positive power and cooler colors for negative power. (b) Total power distribution for the standard vowels [ $\varepsilon]$ (left) and [I] (middle) in the underspecified/small F1 distance condition. The difference plot (right) indicates at least two regions (dashed rectangles) where the power for $[\varepsilon]$ was lower than the power for [r]: prestimulus $(\sim-50 \mathrm{~ms})$ and $\sim 300--400 \mathrm{~ms}$ poststimulus. Onset of the standard is $0 \mathrm{~ms}$ on the $x$ axis. Power values are color coded in arbitrary units (a.u.). Modified from Scharinger et al. (2016) with permission from Elsevier.

\section{*LARGE FIGURE*}




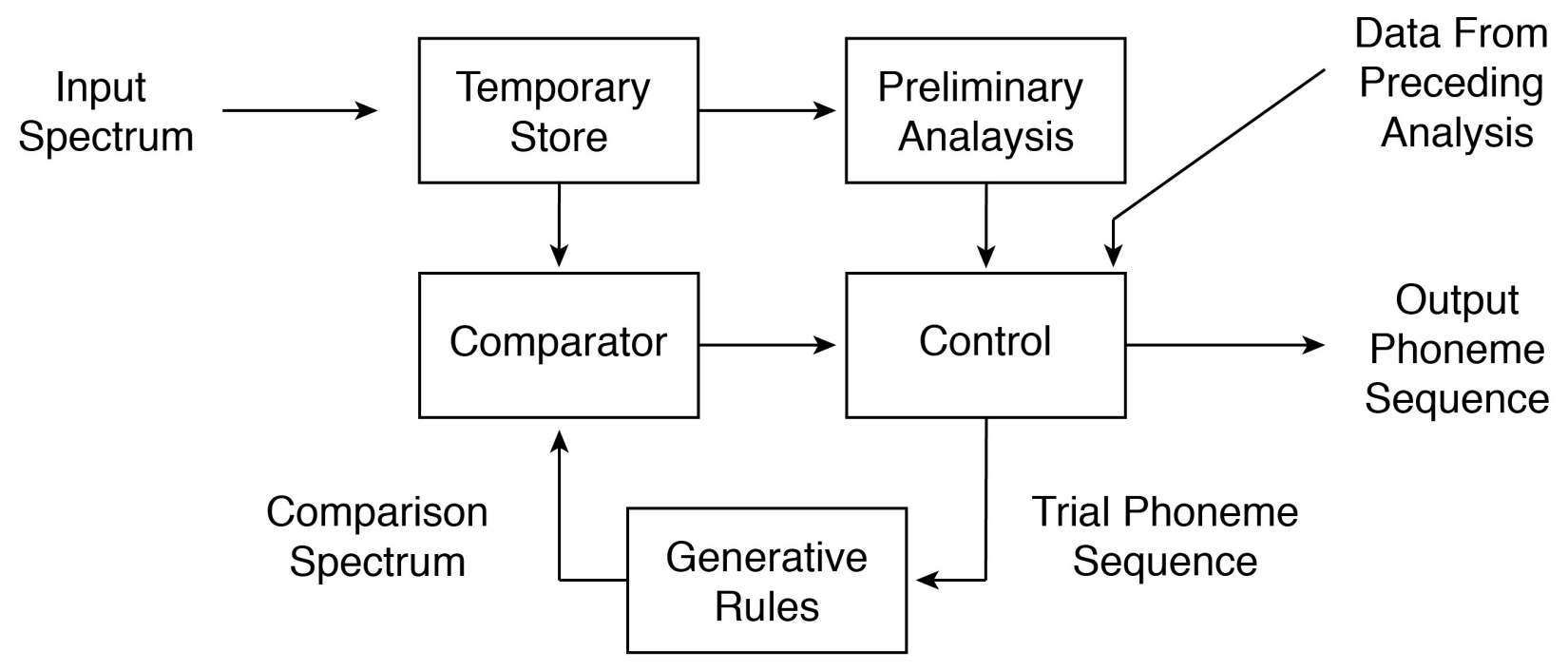

Figure 1 
A

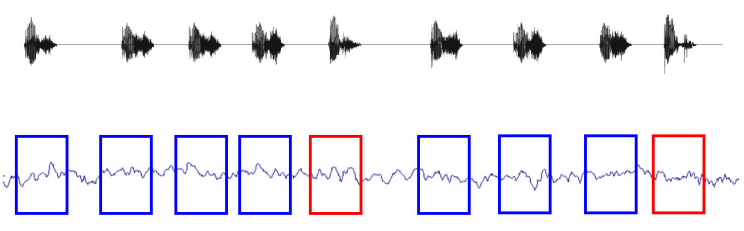

B

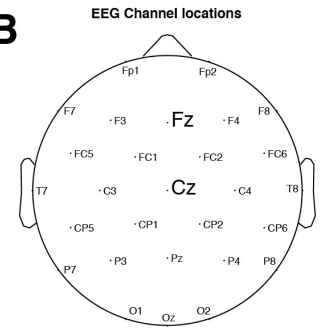

$\mathrm{Fz}$

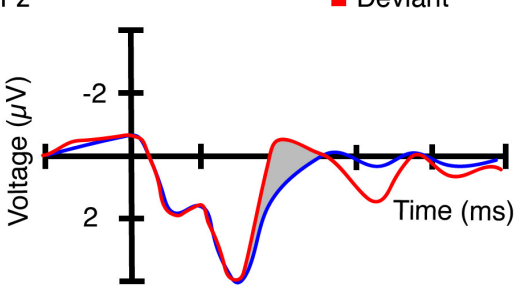

c

C

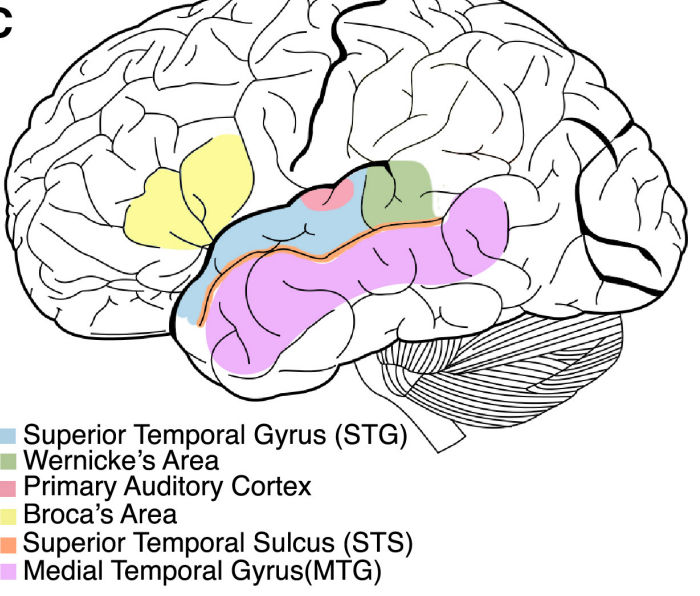

Figure 2 
A Large F1 distance
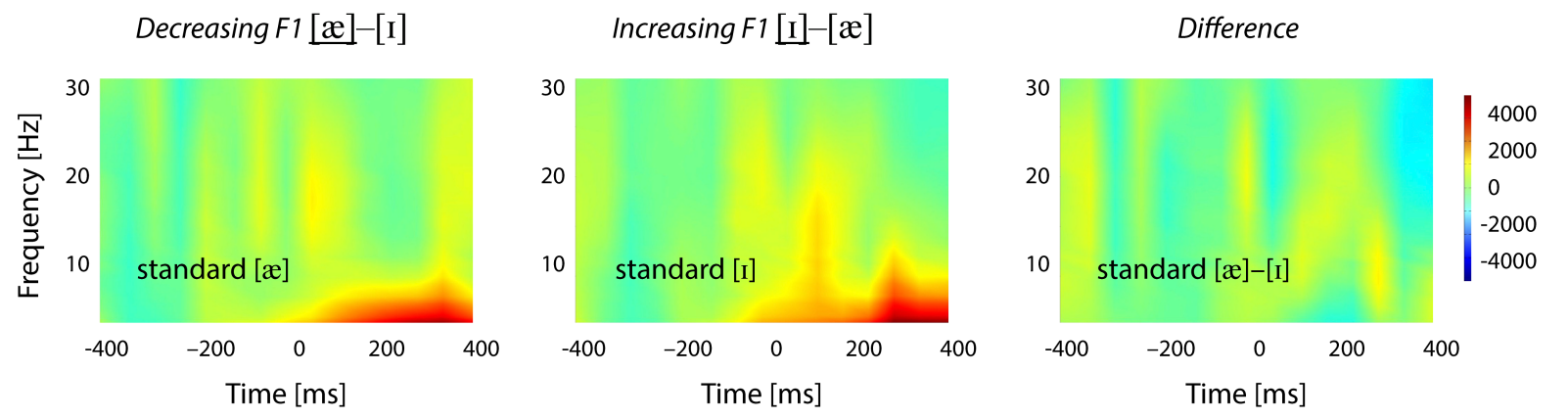

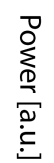

B Small F1 distance
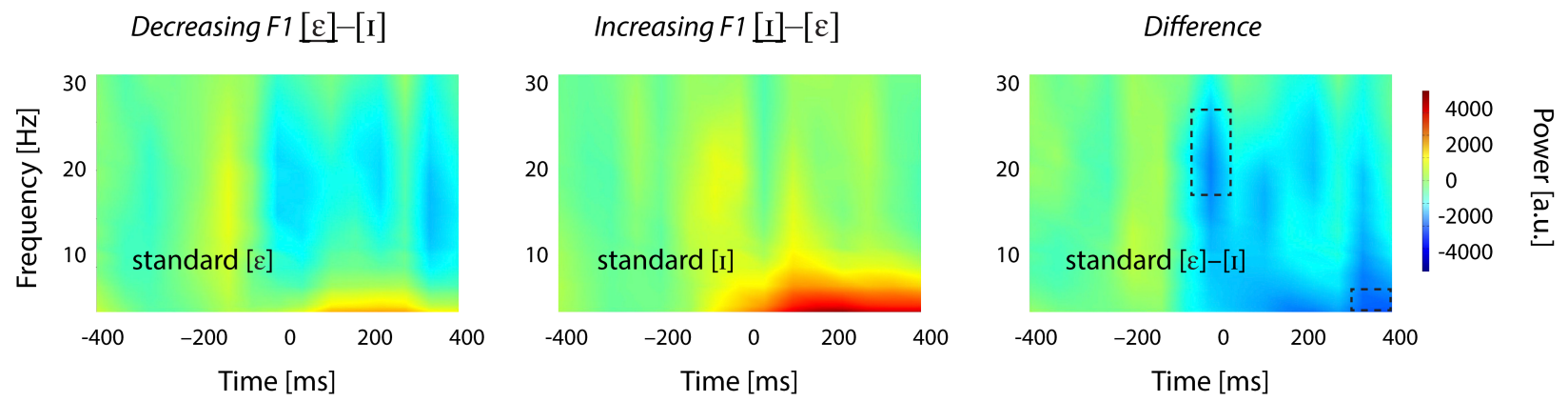

Figure 3

(see manuscript for captions) 